\title{
ResearchOnline@JCU
}

This is the Accepted Version of a paper published in the journal Biological Reviews:

Cowman, Peter F., Parravicini, Valeriano, Kulbicki, Michel, and Floeter, Sergio R. (2017) The biogeography of tropical reef fishes: endemism and provinciality through time.

Biological Reviews. 92 (4). pp. 2112-2130.

http://dx.doi.org/10.1111/brv.12323 


\section{The biogeography of tropical reef fishes: endemism and}

\section{2 provinciality through time}

4 Peter F. Cowman ${ }^{1,2,}$, Valeriano Parravicini ${ }^{3}$, Michel Kulbicki ${ }^{4}$ and Sergio R.

5 Floeter $^{5}$

$7 \quad{ }^{1}$ Department of Ecology and Evolutionary Biology, Yale University, New Haven

8 CT06511, USA

$9 \quad{ }^{2}$ Centre of Excellence for Coral Reef Studies, James Cook University, Townsville, QLD

10 4811, Australia

$11{ }^{3}$ USR 3278 EPHE-CNRS-UPVD, Labex Corail, CRIOBE, 58, Avenue Paul Alduy, 66860

12 Perpignan, France

$13{ }^{4}$ Institut de Recherche pour le développement (IRD), UMR Entropie- Labex CORAIL,

14 Université de Perpignan, Perpignan, France

$15{ }^{5}$ Marine Macroecology and Biogeography Lab., Depto. de Ecologia e Zoologia, CCB,

16 Universidade Federal de Santa Catarina, Florianópolis, Brazil

19 *Author for correspondence (Tel.: +617 4781 3194; E-mail: peter.cowman@jcu.edu.au).

21 ABSTRACT

22 The largest marine biodiversity hotspot straddles the Indian and Pacific Oceans, driven

23 by taxa associated with tropical coral reefs. Centred on the Indo-Australian Archipelago

24 (IAA), this biodiversity hotspot forms the 'bullseye' of a steep gradient in species

25 richness from this centre to the periphery of the vast Indo-Pacific region. Complex

26 patterns of endemism, wide-ranging species and assemblage differences have obscured

27 our understanding of the genesis of this biodiversity pattern and its maintenance across

28 two-thirds of the world's oceans. But time-calibrated molecular phylogenies coupled with

29 ancestral biogeographic estimates have provided a valuable framework in which to

30 examine the origins of coral reef fish biodiversity across the tropics. Herein, we examine 
31 phylogenetic and biogeographic data for coral reef fishes to highlight temporal patterns of

32 marine endemism and tropical provinciality. The ages and distribution of endemic

33 lineages have often been used to identify areas of species creation and demise in the

34 marine tropics and discriminate among multiple hypotheses regarding the origins of

35 biodiversity in the IAA. Despite a general under-sampling of endemic fishes in

36 phylogenetic studies, the majority of locations today contain a mixture of potential paleo-

37 and neo-endemic fishes, pointing to multiple historical processes involved in the origin

38 and maintenance of the IAA biodiversity hotspot. Increased precision and sampling of

39 geographic ranges for reef fishes has permitted the division of discrete realms, regions

40 and provinces across the tropics. Yet, such metrics are only beginning to integrate

41 phylogenetic relatedness and ancestral biogeography. Here, we integrate phylogenetic

42 diversity with ancestral biogeographic estimation of lineages to show how assemblage

43 structure and tropical provinciality has changed through time.

45 Key words: biodiversity, biogeography, provinciality, assemblage similarity, coral reef

46 fishes, endemism, hotspot.

CONTENTS

I. Introduction

II. Biodiversity in the marine tropics

(1) What constitutes a marine biodiversity hotspot?....

(2) The available data.

53 III. The nature of endemism in the marine tropics.

(1) What is a marine endemic species?

(2) The birth and death of endemic species

(3) Temporal patterns in tropical marine endemism

(4) Endemism and 'centres of' - hypotheses still requiring data.......

(2) The hopping hotspot. 
(1) Tropical provinciality in the present 20

(2) Tropical provinciality in the past 22

(3) Analytical considerations 25

VI. Future directions 26

VII. Conclusions 28

VIII. Acknowledgments.

IX. References.

\section{INTRODUCTION}

71 The distribution of tropical fishes and their enigmatic association with reef-building

72 corals has long been of interest in biodiversity science. While tropical reefs only account

73 for $0.1 \%$ of the ocean's surface, over 6,300 species of fish ( $40 \%$ of all marine fishes;

74 Parravicini et al., 2013) and over 790 zooxanthellate species of coral ( $\sim 30 \%$ of all coral

75 species; Veron et al., 2009) are found therein. A latitudinal cline in reef-associated

76 diversity mirrors that observed in terrestrial groups (Willig, Kaufman \& Stevens, 2003;

77 Hillebrand, 2004; Tittensor et al., 2010), while a longitudinal decline in species richness

78 can be identified away from a bullseye of species richness centred in the Indo-Australian

79 Archipelago (IAA). The IAA forms a large area of multitaxon diversity (Tittensor $e t$

80 al., 2010). There are several other names and delineations for this biodiverse region (Fig.

81 1A; for review see Hoeksema, 2007). The IAA has a broad geographic spread and

82 encompasses the world's most complex archipelago (Bellwood, Renema \& Rosen, 2012),

83 housing the vast continental reefs of Southeast Asia, Indonesia, the Philippines, Papua

84 New Guinea and the Great Barrier Reef (Bellwood \& Hughes, 2001). However, there are

85 a number of characteristics of the IAA hotspot that have confounded the study of its

86 genesis (Cowman, 2014). In addition to its central hotspot and the associated gradient in

87 fish diversity, multiple endemic centres exist, mostly on its periphery (Fig. 1A; Roberts et 88 al., 2002; Hughes, Bellwood \& Connolly, 2002), with the bulk of the diversity pattern 89 being formed by medium- and wide-ranging species. Due to a dominance of soft barriers

90 to gene flow across the Indo-Pacific (Cowman \& Bellwood, 2013b), many species are 91 able to maintain continuous ranges from the east coast of Africa to the west coast of the 92 Americas (Lessios \& Robertson, 2006). Permeable, or transient barriers have resulted in 
93 vicariance among clades and species sister pairs, with population structuring present

94 across Indo-Pacific provinces for some species, but not others (Craig et al., 2007; Horne

95 et al., 2008; Gaither et al., 2009). Regional assemblages and biogeographic structures in

96 species composition have been identified (Fig. 1B; Kulbicki et al., 2013), but the extent

97 and position of boundaries is variable according to the authors and the techniques

98 employed (Spalding et al., 2007; Floeter et al., 2008; Kulbicki et al., 2013; Keith et

99 al., 2013; Briggs \& Bowen, 2013). The delineation of both genetic barriers and

100 boundaries for regional assemblages are important steps in evaluating conservation

101 priorities in both terrestrial and marine environments (Whiting \& Lawler, 2000; Olson et

102 al., 2001; Carpenter et al., 2011; Toonen et al., 2011). Such regional schemes can also

103 inform a deep-time understanding of the historical processes that have shaped past and

104 present-day biodiversity patterns (Renema et al., 2008; Bowman et al., 2010; Cowman \&

105 Bellwood, 2013a; Bowen et al., 2013; Bender et al., 2013).

106 The conflict between marine endemism and biodiversity hotspots, diversity

107 gradients and provinciality, has made it difficult to discern the underlining processes

108 generating and maintaining biodiversity patterns on deep and shallow timescales.

109 However, during the last decade intersection among fields of molecular phylogenetics,

110 palaeontology and biogeography has allowed researchers to examine processes

111 underpinning the evolution of coral reef ecosystems and the biodiversity they support.

113 II. BIODIVERSITY IN THE MARINE TROPICS

114 (1) What constitutes a marine biodiversity hotspot?

115 The description of terrestrial biodiversity hotspots based on plant endemism and a

116 measure of habitat degradation has been commonplace since the late 1980s (Myers, 1988;

117 Myers et al., 2000). Such descriptions have provided a valuable tool in the conservation

118 of biodiversity across terrestrial taxonomic groups with regular updates on both the status

119 of these hotspots and the addition of new ones (www.conservation.org). Yet, in the

120 marine realm, the designation of biodiversity hotspots has proved difficult with often

121 conflicting results (Roberts et al., 2002; Hughes et al., 2002; Mora, Tittensor \&

122 Myers, 2008). The conflict arises from incongruence between centres of endemism and

123 centres of total species richness (Fig. 2; Hughes et al., 2002), a pattern that can also be 
124 seen on land in birds (Orme et al., 2005). How one defines an endemic species also

125 impacts observed patterns of endemism (Fig. 2B-D; Hughes et al., 2002; Mora et

126 al., 2008). Although marine biodiversity hotspots have been delineated based on

127 endemism and threat assessment (Fig. 1A; Roberts et al., 2002; Parravicini et al., 2014),

128 some areas of higher species richness of wider ranging taxa (e.g. the Great Barrier Reef)

129 are not considered 'true' hotspots by this definition. Indeed, there is ample evidence to

130 show that the majority of endemic centres of biodiversity are peripheral when compared

131 to the centre of highest diversity across the Indo-Pacific (Fig. 2; Bellwood et al., 2012).

132 The centre of highest biodiversity (the 'bullseye' in the biodiversity gradient) for fishes

133 lies within the IAA (Fig. 2A). How the IAA hotspot was formed, and its role in

134 generating diversity across the Indo-Pacific has been a contentious topic with multiple

135 hypotheses and little consensus (but see Cowman \& Bellwood, 2013a; Bowen et

136 al., 2013).

137 Today, the IAA marine biodiversity hotspot and its associated gradients span two-

138 thirds of the global tropics. However, on an evolutionary timescale it represents a pattern

139 that has been shaped across at least the last 50 million years (Renema et al., 2008). The

140 global hotspot in marine biodiversity literally moved across the globe, even beyond the

141 Indo-Pacific, and so a global context is needed to reveal its origins. The re-centring of the

142 biodiversity hotspot and the eastward shift in its diversity gradient is linked to a series of

143 tectonic, eustatic, climatic, oceanographic and geologic (TECOG) events (Bellwood et

144 al., 2012). These TECOG events have altered the distribution of carbonate platforms and

145 modified the rates of speciation and extinction of ancestral fish lineages (Cowman \&

146 Bellwood, 2011; Dornburg et al., 2015). The combination of palaeontological data and

147 molecular phylogenies has allowed us to track the evolution of the IAA hotspot, but

148 questions still remain regarding the dominant processes of biodiversity creation and

149 maintenance, inside and outside of the IAA (Cowman, 2014).

150 Although much biodiversity research has focused on the description of patterns of

151 a particular system or specific group, during the last five years there has been an

152 increasing effort to quantify biodiversity in terms of assemblage differences and species

153 turnover among locations along the diversity gradient (Leprieur et al., 2012; Kulbicki et

154 al., 2013; Mouillot et al., 2013; Parravicini et al., 2014). These metrics are also being 
155 explored at the population level in an effort to identify significant areas of genetic

156 diversity (Liggins et al., 2015). While this can be a difficult task (Mouillot et al., 2013)

157 and often question-driven, it is an essential part of biogeographic science. Understanding

158 how and why biodiversity changes along a gradient and how regional and local species

159 pools are structured has a vital part to play in the guidance of conservation initiatives

160 (Whittaker et al., 2005). In the case of tropical reef assemblages there are a number of

161 schemes that delineated realms, regions, provinces and ecoregions based on shared

162 environmental traits (Spalding et al., 2007), composition of endemic taxa (Briggs \&

163 Bowen, 2012, 2013) and measures of species dissimilarity (Floeter et al., 2008; Kulbicki

164 et al., 2013). The scheme presented by Kulbicki et al., (2013) (Fig. 1B) integrates a large

165 database of geographic ranges for over 6,300 reef-associated fishes (Parravicini et

166 al., 2013). The resulting scheme appears to reflect historical differences among regions

167 (Cowman \& Bellwood, 2013a), with present-day biodiversity best predicted by past

168 habitat stability and fragmentation (Pellissier et al., 2014). However, it remains unclear

169 whether any provincial scheme based on current species distributions has had

170 macroevolutionary significance in the past (Cowman, 2014). To investigate the historic

171 relevance of extant biogeographic delineations a phylogenetic perspective is required,

172 incorporating estimates of ancestral biogeographic ranges.

173 Questions regarding centres of endemism and biodiversity of reef fishes, the

174 categorization of regional assemblages and their ancestral biogeography require further

175 discussion and analysis. Herein, we present an overview of the recent literature and

176 advances on these topics, alongside new analyses of assemblage dissimilarity through

177 time.

178

179 (2) The available data

180 Although phylogenies for the major groups that are classically considered 'reef fish

181 families' remain incomplete (Cowman, 2014) the most iconic families that have been

182 calibrated with fossil data have provided much insight into early diversification and

183 trophic evolution on coral reefs. The fossil records for these reef fish groups, while

184 sparse, still provide critical evidence for the morphological and ecological expansion of

185 reef-associated fish lineages (Goatley, Bellwood \& Bellwood, 2010; Friedman, 2010). 
186 The combination of both the fossil record and molecular phylogenies has given us a 187 broad understanding of the different phases in the evolutionary relationships between 188 fishes and coral reefs (Bellwood et al., 2015; Bellwood, Goatley \& Bellwood, 2016).

189 Recent efforts have resulted in a large database of species ranges and detailed species 190 checklists for locations across the global tropics (Kulbicki et al., 2013; Parravicini et 191 al., 2013). The combination of these data with phylogenetic hypotheses for those sampled

192 reef fish groups are providing significant insight into the origins of biodiversity patterns 193 and the ancestral biogeography of global tropical assemblages.

\section{THE NATURE OF ENDEMISM IN THE MARINE TROPICS}

\section{(1) What is a marine endemic species?}

198 An endemic species can be defined as a species that has an exceptionally small

199 geographic range and as such presents a priority for conservation (Myers et al., 2000).

200 This view of endemic species being of exceptional importance for conservation is related

201 to the 'double jeopardy' concept - a terrestrially biased observation of a strong positive

202 link between geographic distribution and abundance (Blackburn, Cassey \& Gaston, 2006)

203 that has formed a basis for the assessment of extinction risk (Pimm et al., 2014).

204 However, such a link may not exist for reef corals and associated fishes, where the

205 abundances of endemic and pandemic species are equally broad (Hughes et al., 2014),

206 with some endemic species showing higher recruitment in certain locations (DeMartini \&

207 Friedlander, 2004). Endemics have also traditionally been viewed as representing young

208 species at their location of origin, with their use in demarking terrestrial biodiversity

209 hotspots validated by concordant patterns of total diversity across multiple groups (Myers

210 et al., 2000; Mittermeier et al., 2005, 2011). Yet, across the tropics there is no

211 concordance between centres of endemism and centres of total biodiversity in reef-

212 associated fishes (Fig. 2) or reef-building corals (Hughes et al., 2002). It has been

213 difficult to classify a marine endemic species, especially because of the subjectivity in

214 defining what is an 'exceptionally small' range. In the marine realm, there is also the

215 issue of habitat continuity, particularly in coral reef systems where the distribution of

216 habitat is often patchy with varying degrees of distance between patches. Previous 
217 assessments of reef fish endemism have taken a regional or provincial approach

218 (Randall, 1998; Mora et al., 2003; Floeter et al., 2008; Cowman, 2014) or defined

219 endemism by per cent of all geographic range areas recorded (Connolly, 2005; Kulbicki

220 et al., 2013) or by absolute area, which has generally been defined as areas less than the

221 size of the Hawaiian archipelago $\left(1.3 \times 10^{6} \mathrm{~km}^{2}\right.$; Bellwood \& Meyer, 2009b) but smaller

222 areas have been used $\left(0.5 \times 10^{6} \mathrm{~km}^{2}\right.$; Hughes et al., 2002). By comparing different

223 endemic schemes based on the largest fish geographic database to date (Fig. 2B-D) we

224 can identify both conflict and agreement among assigned centres of endemism and their

225 relationship to centres of biodiversity.

226 Overall, the centre of highest total biodiversity is located in the Coral

227 Triangle/Sunda Shelf areas (Fig. 2A), which is characterized by low endemic species

228 richness (Fig. 2B-D). Conflict with previous studies likely stems from the size and

229 delineation of locations (Mora et al., 2003). Here, we consider the ecoregional scheme of

230 Spalding et al. (2007), which may not reflect biogeographic boundaries and true genetic

231 connectivity across localities, particularly in the ecoregions that define the Coral Triangle

232 (Treml et al., 2015). However, these patterns are similar to previously reported patterns

233 for an earlier dataset based on location checklists (Parravicini et al., 2013) with similar

234 (but not concordant) patterns reported for endemic coral species richness (Hughes et

235 al., 2002). Longitudinal peripheral locations stand out as having equal or higher density

236 of endemic species compared to the central hotspot (top margin plots in Fig 2B-D), and

237 in having endemic species in higher proportions of the total species pool (Fig. 3A). It is

238 interesting to note that the Great Barrier Reef (GBR) appears to have low endemism

239 across any scheme, but is very high in species richness of medium- and wide-ranging

240 taxa across multiple groups (Roberts et al., 2002). Given the concerns regarding the

241 health and status of the GBR (Hughes, Day \& Brodie, 2015), conservation efforts are also

242 important for areas that support wide-ranging species, not considered by traditional

243 hotspot analysis (Roberts et al., 2002; Hughes et al., 2002).

245 (2) The birth and death of endemic species

246 An endemic species can represent a lineage at the beginning of its evolutionary life (neo-

247 endemic) or the end of its life before becoming extinct (paleo-endemic; Bellwood \& 
248 Meyer, 2009b). The range of a neo-endemic species should reflect its location of

249 inception, i.e. its position when as a sub-population it became spatially and/or genetically

250 isolated from its parent lineage, through any number of allopatric, sympatric or peripatric

251 scenarios (Gaston, 2003; Coyne \& Orr, 2004; Rocha et al., 2005b; Hodge et al., 2013).

252 Paleo-endemics on the other hand, arise through range contraction relating to processes

253 of extinction, i.e. a former widespread species becomes locally extinct across its range,

254 with its current endemic position reflecting its last site of survival. A third scenario can

255 also be imagined, where an endemic species arose in a particular location, and due to

256 some ecological or geographic constraint has remained there to the present day without

257 significantly expanding or contracting its range (e.g. endemics in the Red Sea; DiBattista

258 et al., 2016a) Such 'ecological' endemics may be particularly suited to their native range

259 and as such could become locally dominant compared to pandemic congeners, perhaps

260 supporting the observed lack of pattern between geographic extent and abundance

261 (Hughes et al., 2014). Distinguishing between paleo-, neo-, or ecological endemism

262 requires temporal, biogeographic and ecological insight into their origins and persistence.

263 Whether endemic species are at the beginning of their evolutionary life or at the end

264 has called into question their value in delineating locations of significant species

265 accretion, marine biodiversity hotspots, and their role in the origins of Indo-Pacific

266 tropical biodiversity (Bellwood \& Meyer, 2009a; 2009b; Briggs, 2009; Bowen et

267 al., 2013). However, understanding how endemism has arisen through processes of local

268 speciation and/or pandemic extinction is an important aspect of how biodiversity patterns

269 are generated in marine systems. How endemic lineages have arisen through time has

270 implications for both the relationship between lineage age and geographic range, and the

271 primary modes by which speciation occurs in coral reef systems (Hodge et al., 2012;

272 Hodge, van Herwerden \& Bellwood, 2014). Determining the geographic distribution of

273 paleo- and neo-endemism should provide an outline of areas or time periods that have

274 been important for species origin (macroevolutionary sources) or areas that represent

275 species survival and/or extinction (macroevolutionary sinks). Source and sink areas for

276 biodiversity may not be mutually exclusive (Bowen et al., 2013), adding another dynamic

277 facet to the accretion and maintenance of tropical biodiversity. 


\section{(3) Temporal patterns in tropical marine endemism}

280 Given adequate fossil evidence for a lineage it may be possible to distinguish between

281 paleo- and neo-endemism (Bellwood \& Meyer, 2009b). Without such fossil records, it

282 remains to be seen if such endemic processes can be recorded in dated molecular

283 phylogenies. If the assumption that neo-endemics are represented by relatively young

284 lineages and paleo-endemics by comparatively older lineages holds true, then dated

285 phylogenies of reef-associated fishes may allow us to examine the distribution of paleo-

286 versus neo-endemism across the tropics. From a list of over 600 species classified as

287 having an endemic range (based on the top 10\% of all sampled species when ranked from

288 smallest to largest range size; Parravicini et al., 2014) only $\sim 17 \%$ of these species have

289 an associated age estimate from a published, calibrated time tree (Fig. 3B). This

290 incomplete phylogenetic and taxonomically biased sampling (Table 1) is a primary

291 obstacle to investigating temporal patterns of endemism that requires further attention in

292 the future. A secondary obstacle is to decide what evolutionary age distinguishes a paleo-

293 from a neo-endemic. Here, we use a cut-off of less than or equal to 2.6 million years ago

294 (Ma) for a neo-endemic with greater than 2.6 Ma defining a paleo-endemic (Fig. 3B).

295 This marks the beginning of the Quaternary, a time period characterized by over 30

296 glacial-interglacial cycles associated with repeated cooling and warming which had

297 consequences for reef habitat stability and the diversification of many associated fish

298 lineages (Pellissier et al., 2014). While there are many extant lineages of Quaternary age

299 and younger (of various geographic size) the majority of extant reef-associated species

300 date to the Miocene ( 23-5.3 Ma) and Pliocene ( 5.3-2.6 Ma) epochs (Cowman, 2014;

301 Hodge et al., 2014; Bellwood et al., 2016). For these 17\%, there appears to be very little

302 temporal signal in the ages of endemic lineages (Fig. 3B).

303 Although there is a general trend of increasing numbers of endemic lineages towards

304 the present day, this is most likely an artefact of increasing node density and 'the pull of

305 the present' (Pybus \& Harvey, 2000). When comparing the distribution of neo-versus

306 paleo-endemism there are as many species in our neo-endemic cut-off period as there are

307 from 2.6-5.2 Ma ( 23\% of the sample in each time period), with many more paleo-

308 endemics distributed throughout the Miocene epoch ( $48 \%$ of the whole sample). From a

309 geographic perspective, the patterns of endemism are also not clear. Fig. 3A displays the 
310 proportion of each ecoregion assemblage that is made up by endemics, and when those 311 endemic taxa have a published age estimate, whether it represents neo-endemism, paleo-

312 endemism or a mixture of both. In addition to there being higher numbers of endemic reef

313 fishes in peripheral locations in the Indo-Pacific and the Atlantic realms, fish endemism

314 in this sampled data set forms a higher proportion of local assemblages. In the Pacific,

315 proportions of endemics in location assemblages are higher in island areas such as

316 Hawaii (16.5\%), the Galapagos (13\%), Easter Island (32\%) and Juan Fernández Island

317 (73\%). These locations have varying degrees of isolation from the core Indo-Pacific

318 biodiversity hotspot with faunal breaks recognized in some taxonomic assemblages (e.g.

319 corals; Keith et al., 2013). In the Atlantic, locations such as St. Helena and Ascension

320 Islands, and Cape Verde display higher proportions of endemics (24\% and 12\%,

321 respectively) when compared to coastal regions. It must be noted that published estimates

322 of fish endemism in these Pacific and Atlantic locations do vary from the data examined

323 here (estimated endemism in each location $25 \%, 11.7 \%, 22 \%, 87.5 \%, 26 \%, 30 \%$,

324 respectively; Randall, 2007; Allen, 2008; Floeter et al., 2008; Randall \& Cea, 2011;

325 Friedlander et al., 2016).

326 These discrepancies highlight the impact a definition of endemism can have on

327 assessments of local endemism. An extreme case of this can be seen in a recent

328 assessment of endemism in the Red Sea (DiBattista et al., 2016b). DiBattista et al.

329 (2016b) calculated 12.9\% endemism for the entire Red Sea region, while our estimates of

330 numbers of endemics are low or zero for each of our defined categories (Fig. 2B-D).

331 Aside from minor taxonomic sampling differences, this is likely due to the geographic

332 size cut-off in our per cent endemism definition $\left(<12,550 \mathrm{~km}^{2}-\right.$ top $10 \%$ of species

333 ranges ranked from smallest to largest) and the splitting of the Red Sea into two

334 ecoregions under our ecoregion assessment (Northern and Central, and Southern Red

335 Sea; Spalding et al., 2007). If we consider a larger area cut-off of $5 \times 10^{5} \mathrm{~km}^{2}$ (cf. Hughes

336 et al., 2002), per cent endemism based on this data set increases to $\sim 23 \%$ in the entire

337 Red Sea province. Variation in ecoregional assessments for the Caribbean region

338 (Robertson \& Cramer, 2014) and the North and East coast of Brazil (Floeter et al., 2008)

339 will result in different estimates for local and regional endemism. Future examination of

340 patterns of reef fish endemism may require the integration of both local and regional- 
341 scale assessments ( $c f$. Borsa et al., 2016), incorporating issues related to geographic scale

342 and how endemism is identified.

343 In terms of lineage ages, there is a dramatic lack of phylogenetic sampling of endemic

344 species within Central Indo-Pacific and coastal Atlantic locations (Fig. 3A). This is

345 probably a general artefact of the likelihood of sampling an endemic species along the

346 biodiversity gradient, and the difficulties associated with sampling peripheral locations.

347 For those locations where endemic age estimates are available, some broad patterns

348 emerge. The majority of ecoregions show either a mix of both paleo- and neo-endemism

349 (e.g. Hawaii, Agulhas Bank, Natal, Cape Verde), or are completely paleo-endemic (e.g.

350 Galapagos, Juan Fernández, Easter Island, Kermadec Island). Only two ecoregions

351 contain species whose lineage age is less than 2.6 Ma: Marshall and Society Islands,

352 however only one lineage is sampled in each case and both areas have very low

353 endemism $(<3 \%)$. The majority of species defined as paleo-endemic are found in the

354 Tropical East Pacific and Atlantic regions. This may be evidence of higher turnover of

355 assemblages over time in these regions with older endemic ages linked to the high rates

356 of extinction observed there (Budd, 2000). The mixture of endemic ages in the Indo-

357 Pacific realm reflects a complex biogeographic and vicariant history. On the other hand,

358 in the Indo-Pacific there appears to be more stable reef habitat in the last 3 million years

359 that has provided a possible refuge from extinction for older lineages, with fragmentation

360 and isolation of distant stable habitat patches driving younger speciation (Cowman \&

361 Bellwood, 2011; Pellissier et al., 2014). Our general pattern of mixed endemic ages in the

362 majority of Central Indo-Pacific areas may reflect the broader pattern of lineage ages

363 observed across the Indo-Pacific, where areas that have been in close proximity to stable

364 reef refugia in the last 3 million year, display larger differences in the ages of reef fish

365 lineages found there (Pellissier et al., 2014). The effect of stable reef habitat can also be

366 noted in the phylogenetic structure of assemblages where more stable areas are more

367 phylogenetically clustered (Leprieur et al., 2016a).

368 The paleo-versus neo-endemism discussion can be likened to that of the

369 museum/cradle analogy, where locations that act as a museum can harbour older lineages

370 through increased survival or isolation (macroevolutionary sinks, or 'graveyards' for

371 diversity), while cradles of diversity act as location of species inception 
372 (macroevolutionary source, or 'wellspring' of diversity; Bowen et al., 2013). There is

373 ample evidence to show that tropical coral reefs have acted as both museums and cradles

374 for biodiversity on different temporal and geographic scales (Kiessling, Simpson \&

375 Foote, 2010; Cowman \& Bellwood, 2011; Bellwood et al., 2012; Briggs \&

376 Bowen, 2013). The museum/cradle pattern of biodiversity evolution has also been

377 associated with the latitudinal diversity gradient (LDG) in both marine (Jablonski, Roy \&

378 Valentine, 2006) and terrestrial settings (McKenna \& Farrell, 2006; Moreau \&

379 Bell, 2013). Although many hypotheses have been used to examine the LDG, their utility

380 in explaining the longitudinal gradient in this marine system has been limited

381 (Rosen, 1984). For the longitudinal gradient, several cornerstone hypotheses have

382 generally been discussed (Bellwood et al., 2012; Barber \& Meyer, 2015). But it is only in

383 the last five years where dated phylogenies for the groups that form this pattern have

384 been used to assess these long-standing hypotheses from a temporal perspective.

\section{(4) Endemism and 'centres of' - hypotheses still requiring data}

387 The popular perceptions of the IAA hotspot (or the more restricted Coral Triangle 388 region) as a significant centre of species origin (CoOr; Ekman, 1953), a centre of overlap 389 among Indian and Pacific biotas (CoOl; Woodland, 1983), or a centre of species 390 accumulation/survival (CoAc/CoSr; Ladd, 1960; Heck \& McCoy, 1978) have been 391 assessed using dated phylogenies and ancestral biogeographic estimation. Some of these 392 hypotheses (or variants of them) have held the distribution of endemic species across the 393 Indo-Pacific gradient as a distinguishing factor (Potts, 1985). Originally summarized by

394 Potts (1985) for coral species, the assumptions and implications of each of these 395 cornerstone and subsequently derived models are numerous (reviewed by Bellwood et 396 al., 2012).

397 For the CoOr model, there should be a preponderance of young endemics in the 398 centre of the hotspot forming a 'fountain' or cradle for new species, with the gradient in 399 richness the result of older species expanding their range, or gradually becoming 400 displaced by superior competitors from the centre (Stehli \& Wells, 1971; Briggs, 2000). 401 The predictions of the $\mathrm{CoOl}$ model are less aimed towards the age of endemics and more 402 towards the location of species origin (Bellwood et al., 2012), being on the peripheral 
403 oceanic islands (Rosen, 1984). Overall, there should be more small or endemic ranges on

404 either side of biogeographic boundaries, with wide-ranging sister pairs of species

405 overlapping in the centre of the hotspot (Gaither \& Rocha, 2013). But, the CoOl model

406 assumes symmetry in speciation forcing factors either side of biogeographic boundaries.

407 In the case of the Indian and Pacific Oceans there is a strong asymmetry in patterns of

408 isolation (or connectivity). While the Pacific is dominated by stepping stone processes,

409 the Indian Ocean provides a continuum of continental masses. These result in very

410 different distributions of endemism, with the exception that in both oceans endemism

411 tends to increase in peripheral regions (Red Sea and South West Indian Ocean; Hawaii,

412 Marquesas, Easter Island and Kermadec in the Pacific). The CoAc model, similar to the

$413 \mathrm{CoOl}$ model, has species arising on the peripheral oceanic islands and gradually moving

414 into the centre, but does not require geographic overlap of closely related species.

415 No single 'centre of' process appears to be responsible for the current temporal

416 and geographic pattern of endemic reef fishes (Fig. 3), although important age estimates

417 for endemic taxa in the hotspot centre are still required. The majority of locations seem to

418 support both old and young endemics. Similarly, published evidence in the temporal and

419 geographic structuring of species and populations reflect patterns of IAA origination

420 (Timm \& Kochzius, 2008), overlap (Hubert et al., 2012; Gaither \& Rocha, 2013) and

421 accumulation (Kool et al., 2011) in different taxa. But previous studies across fishes,

422 corals and molluscs fail to show any broadscale evidence of any of the core models

423 (Halas \& Winterbottom, 2009) despite these groups showing similar patterns of tropical

424 diversity (Roberts et al., 2002). The underlying process appears more dynamic with

425 multiple roles played by both centres of endemism and centres of biodiversity (Bowen et

426 al., 2013) that are likely to act on different timescales (Renema et al., 2008; Cowman \&

427 Bellwood, 2013b; Pellissier et al., 2014).

428 Other models of Indo-Pacific biodiversity evolution have included the distribution

429 of widespread species (Connolly, 2005) and the role played by extinction (McCoy \&

430 Heck, 1976; Barber \& Bellwood, 2005). The mid-domain effect (MDE; Connolly, 2005)

431 seeks to explain the position of a hotspot 'bullseye' pattern by the random placement of

432 geographic ranges in a bounded domain. In the case of the Indo-Pacific, the MDE

433 explains much of the variation in species richness for fishes and corals among tropical 
434 locations (Bellwood et al., 2005). But significant deviations from a MDE expectation can

435 also be identified in both groups, where the Red Sea/West Indian Ocean and the IAA

436 hotspot stand out as having significantly higher species richness than predicted, while

437 much of the Pacific Ocean is depauperate (Connolly, Bellwood \& Hughes, 2003). The

438 explanatory power and null expectations of the MDE are useful, but still lack an historic

439 perspective (Bellwood et al., 2012).

440 The 'centre of survival' model $(\mathrm{CoSr})$ is a more pluralistic variant of the CoAc

441 model that provides a shift in focus from rates of speciation to rates of extinction (Heck

$442 \&$ McCoy, 1978). Under the CoSr model, speciation can occur at any time or location,

443 but more lineages tend to survive inside the IAA hotspot than outside where extinction is

444 higher (Barber \& Meyer, 2015). Support for the role of the IAA hotspot as a significant

445 centre for lineage survival has come from integrating time-calibrated phylogenies with

446 ancestral biogeographic estimation (Cowman \& Bellwood, 2013a; Dornburg et al., 2015)

447 and from population-level data (Evans et al., 2016). Coral reef occupation appears to

448 provide a refuge effect in some taxa (Cowman \& Bellwood, 2011; Sorenson, Santini \&

449 Alfaro, 2014) with coral reef stability important for the survival of old lineages and the

450 fragmentation of habitat linked to younger diversification in the reef fish families

451 Labridae, Pomacentridae and Chaetodontidae (Pellissier et al., 2014). Our assessment of

452 endemism here may also highlight the primary role of the IAA as a centre of survival.

453 The lower number of endemics in the centre of the hotspot may be an artefact of elevated

454 rates of range expansion through higher concentrations of stable reef area and

455 connectivity leading to more small- to medium-sized ranges that are larger than the

456 endemic range definition. Deviations from the MDE expectation may be concordant with

457 the CoSr, where the enriched IAA is the result of more medium- and small-range species

458 present there (Connolly et al., 2003), but overall rates of origination may not be

459 significantly higher than elsewhere. Recent assessment of the rates of diversification in

460 the clownfish genus Amphiprion showed no significant difference in rate of speciation

461 among the Indian and Pacific Ocean radiations (Litsios et al., 2014). When comparing the

462 biogeographic histories of the Atlantic and the IAA hotspot there are similar patterns of

463 origination, but it is the survival and subsequent cladogenesis of ancestral lineages and 
464 connectivity across the Indo-Pacific domain that have elevated biodiversity within the 465 IAA (Cowman \& Bellwood, 2013a; Bellwood et al., 2015).

\section{ANCESTRAL BIOGEOGRAPHY AND BIODIVERSITY}

468 The tropical world, restricted to the lower latitudes since $\sim 37$ Ma by the Circum-

469 Antarctic Current (Kamp et al., 1990), is broken up into three major longitudinal realms -

470 the Atlantic, the Indo-Pacific and the Tropical East Pacific. A series of barriers have

471 separated these realms sequentially over the past 65 million years: $(i)$ the East Pacific

472 Barrier (EPB) - a $5000 \mathrm{~km}$ expanse of open ocean forming a 'soft' but effective barrier

473 throughout the past 65 million years (Bellwood \& Wainwright, 2002); (ii) the Terminal

474 Tethyan Event (TTE) - a land barrier at the northern tip of the Red Sea marking the final

475 closure of the ancient Tethys Seaway and the low latitude connect between the Atlantic

476 and Indian Ocean, dated between 18 and 12 Ma (Adams, Gentry \& Whybrow, 1983;

477 Steininger \& Rogl, 1984) with evidence of earlier closures (Rogl, 1998); (iii) the Isthmus

478 of Panama (IOP) - the final raising of the land bridge is estimated at between 3.1 and 2.8

479 Ma (Coates \& Obando, 1996; O'Dea et al., 2016) with an extended geological and

480 biological history as far back as the Miocene (Farris et al., 2011; Montes et al., 2015;

481 Bacon et al., 2015a). These barriers have left a marked signal in broad regional measures

482 of assemblage dissimilarity of reef-associated fishes (Floeter et al., 2008; Kulbicki et

483 al., 2013). Both 'soft' and 'hard' barriers can leave a strong signal of vicariance in the

484 evolutionary history of reef-associated lineages (Lessios, 2008). For the wrasses

485 (Labridae), damselfishes (Pomacentridae) and butterflyfishes (Chaetodontidae) an

486 assessment of vicariance by Cowman \& Bellwood (2013b) found that the temporal signal

487 of hard and soft barriers can be quite different, reflecting the history of the isolating

488 mechanism. While these historical barriers have been very effective in isolating these

489 realms, there have been several reports of barrier breaches by lineages (with subsequent

490 speciation) and prolonged genetic connectivity among populations (Rocha et al., 2005a;

491 Lessios \& Robertson, 2006; Bowen et al., 2006). The assemblages that are found in each

492 realm today are the product of a long history of tectonic and climatic turmoil. Changes in

493 the configuration of coral reefs and global provinciality over the past 60 million years can

494 be seen in the fossil and phylogenetic records of associated fish lineages. 


\section{(1) The Atlantic and Indo-Pacific - worlds apart}

A deep split between the extant Atlantic and the Indo-Pacific reef fish assemblages is seen in species checklists (Floeter et al., 2008; Kulbicki et al., 2013, 2014) and in several phylogenetic analyses (Barber \& Bellwood, 2005; Hodge et al., 2013; Cowman \& Bellwood, 2013b). Although many cladogenetic splits occur around the timing of the TTE, there is evidence that points to early divergences across this barrier (Cowman \& Bellwood, 2013b) and fossil indications of earlier endemic reefassociated fauna both in the ancestral Tethys Sea and Caribbean regions (Coates, 1973; Hallam, 1973). Today there are a few notable fish taxa absent from the Atlantic that are present in the Pacific [rabbitfishes (family Siganidae); fusiliers (family Caesionidae); and unicornfishes (genus Naso)], and vice versa (the blenny family Labrisomidae and the parrotfish genus Sparisoma). There are also several genera that show disjunct distributions that indicate either extinction in the West Atlantic or colonization of the East Atlantic from the Indian Ocean. In the case of the surgeonfish genus Naso, a

510 putative sister-lineage fossil from the Caribbean (Tyler \& Sorbini, 1998) provides direct

511 evidence of extinction in the Atlantic realm promoting assemblage differences. Other 512 reef-associated fish genera such as Cirrhitus (hawkfish), Girella (sea chubs) and

513 Prionurus (sawtail surgeonfish) are found in the Indo-Pacific, including the Tropical East

514 Pacific, but are not present in the West Atlantic.

515 Within the Atlantic, some genera have highly skewed distributions. There are 156

516 genera that occur in the New World (both sides of tropical America) but not in the East

517 Atlantic [e.g. grunts (Anisotremus, Haemulon), porgies (Calamus), cleaner-gobies

518 (Elacatinus), and wrasses (Halichoeres/Iridio clades)], while 84 genera display the

519 opposite pattern [e.g. gobies (Gobius, Thorogobius, Wheelerigobius), blennies

520 (Lipophrys), porgies (Pagellus, Spicara) and wrasses (Symphodus)] (Floeter et al., 2008;

521 Levy et al., 2011). Other genera, such as Malacoctenus (blennies), Mycteroperca

522 (groupers), Sparisoma (parrotfishes) and Stegastes (damselfishes), are much more diverse 523 in the West Atlantic (and the Tropical East Pacific) than in the East Atlantic. However, 524 the genera Diplodus (porgies), and Parablennius and Scartella (blennies) are more 525 speciose in the East Atlantic than in the West Atlantic. At least 18 East Atlantic genera 
526 occur in the Indo-Pacific but are not found in the West Atlantic or Tropical East Pacific

527 (e.g. the wrasse genus Coris, the emperor genus Lethrinus and the sweetlips genus

528 Plectorhinchus). These East Atlantic/Indo-Pacific genera indicate either a relatively

529 recent connection via southern Africa (Bowen et al., 2006) or more ancient relictual

530 lineages remaining from an ancestral Tethyan hotspot (Barber \& Bellwood, 2005).

531 However, extinction associated with the collapse of the Tethyan hotspot and the more

532 recent Messinian Salinity Crises in the Mediterranean (Harzhauser et al., 2007; Renema

533 et al., 2008) will have blurred the biogeographic origins of those clades.

535 (2) The hopping hotspot

536 The collapse of the ancestral Tethys hotspot and the survival of lineages in

537 emerging habitat in the Indo-Pacific laid the foundation of modern reef biodiversity

538 (Renema et al., 2008). The fossil record of scleractinian corals shows expansion in the

539 Miocene that is paralleled by accelerated cladogenesis in associated fish lineages

540 (Cowman \& Bellwood, 2011). While the fossil record of reef-associated fishes does not

541 show a clear signal of this ancestral collapse, recent methods combining fossil and extant

542 taxa in an ancestral biogeographic assessment show the potential movement of lineages

543 in the family Holocentridae (squirrel and soldier fishes) from a Tethyan hotspot to an

544 Indo-Pacific one during the Oligo-Miocene (Dornburg et al., 2015). This 'hopping

545 hotspot' pattern described by Renema et al. (2008) highlights how the collapse of

546 ancestral reef habitat is reflected in the distribution of fossil diversity across taxa and the

547 temporal history of molecular lineages ('as hotspots hop, their taxa slide': Bellwood et

548 al., 2012, p. 231). These deep-time distributional changes in biodiversity, numerous hard

549 and soft dispersal barriers, and variation in reef habitat stability mean that provincial

550 delineation of the marine tropics requires discrete temporal investigation.

\section{V. PROVINCIALITY OF THE MARINE TROPICS}

553 Several biogeographic schemes have been superimposed onto the backdrop of the Indo-

554 Pacific diversity gradient. These have been based on numerous criteria (Spalding et

555 al., 2007; Kulbicki et al., 2013; Keith et al., 2013; Briggs \& Bowen, 2013), but as yet

556 there has been little attempt to account for evolutionary relationships or biogeographic 
557 processes. Several studies have employed dated phylogenies and extant geographic

558 distributions to estimate ancestral biogeographic ranges (Tavera, Balart \& Bernadi, 2012;

559 Cowman \& Bellwood, 2013a; Litsios et al., 2014; Dornburg et al., 2015). A popular

560 biogeographic model for these studies has been the dispersal, cladogenesis and extinction 561 model (DEC) of Ree \& Smith (2008). Recently, this model has been extended, allowing

562 the incorporation of a number of other biogeographic scenarios (Matzke, 2013). The

563 conventional likelihood algorithms implemented in the DEC model remain

564 computationally limited (Landis et al., 2013) and biogeographic inference across more

565 than 10 areas becomes unmanageable (Ree et al., 2005). The number of areas can be

566 increased if strict assumptions are made about area occupancy (Webb \& Ree, 2012), but

567 more often geographic distribution data is condensed into less than 10 area assignments,

568 reducing its spatial resolution. However, a recent paper by Landis et al. (2013) outlines a

569 Bayesian approach to ancestral biogeographic estimation across hundreds of areas

570 (BayArea). While this approach does make some strict assumptions and only models a

571 restricted number of biogeographic scenarios (Matzke, 2013) it has the advantage of not

572 being limited by area allocation, allowing biogeographic inference at a much finer scale.

573 In theory, one could assign areas in a gridded manner where biogeographic areas are not

574 well defined (Landis et al., 2013).

575 In the study of reef fish ancestral biogeography, a number of different area

576 definitions have been used (Tavera et al., 2012; Litsios et al., 2014; Dornburg et

$577 a l ., 2015)$. The main differences among the area schemes used are the delineation of

578 discrete provinces within the Indo-Pacific, inclusion of the Coral Triangle as an

579 independent area, and divisions within the Atlantic realm. Kulbicki et al. (2013) outlined

580 a method for delineating tropical regions and provinces based on the dissimilarity of reef

581 fish species assemblages. Their approach followed the methodological framework

582 proposed by Kreft \& Jetz (2010). This statistical approach for assigning areas for

583 biogeographical assessment based on assemblage differences could be used as an initial

584 step in an ancestral biogeographic analysis to achieve a meaningful, taxon-specific

585 delineation of geographic space. Although Kulbicki et al. (2013) did not incorporate

586 phylogenetic history, methods do allow for measures of turnover among locations based

587 on lineages distributed across a phylogenetic tree (Leprieur et al., 2012). By measuring 
588 lineage turnover, we can examine provinciality base on phylogenetic assemblage

589 dissimilarity. Further, by using the BayArea approach to estimate ancestral ranges at

590 internal nodes on a phylogeny we can compare the phylogenetic clustering of present-day

591 assemblages with the phylogenetic clustering of lineages through time.

592 Here, we examine regional dissimilarity, accounting for phylogenetic relatedness,

593 across 111 tropical ecoregions ( $c f$. Spalding et al., 2007) for 11 globally distributed reef-

594 associated fish families (Apogonidae, Acanthuridae, Chaetodontidae, Holocentridae,

595 Labridae, Lutjanidae, Pomacentridae, Pomacanthidae, Sparidae, Tetraodontidae, and

596 Zanclidae). These families vary in richness from the monotypic family Zanclidae to the

597 very diverse Labridae with over 630 species. Dated phylogenies for these families were

598 obtained from a number of published sources (Cowman \& Bellwood, 2011; Choat et

599 al., 2012; Frédérich et al., 2013; Santini et al., 2013; Santini, Carnevale \&

600 Sorenson, 2014; Sorenson et al., 2013; Rabosky et al., 2013; Dornburg et al., 2015), with

601 geographic distributions taken from the largest database of reef fish species ranges

602 (Parravicini et al., 2013). The individual family phylogenies and their associated

603 presence/absence of species across the 111 ecoregions were used for biogeographic

604 analyses in the BayArea program. The resulting biogeographic reconstruction and

605 associated phylogeny was then truncated at 3 million year increments back to $27 \mathrm{Ma}$. At

606 each time point the biogeographically reconstructed ranges and the associated

607 phylogenetic tree was used to cluster ecoregion assemblages based on phylogenetically

608 informed dissimilarity. In order to obtain a metric independent from the richness of

609 lineages, we only used the turnover component of phylogenetic dissimilarity. The results

610 of the phylogenetic dissimilarity clustering for present-day assemblages and across nine,

6113 million year time slices are discussed below.

612

613 (1) Tropical provinciality in the present

614 The present-day provinciality of tropical fish assemblages (Fig. 4) when

615 accounting for phylogenetic relationships shows many similarities with the results of

616 Kulbicki et al. (2013), even though the 11 families examined here are only a subset of the

617 geographic data they examined. There is a basal split between the Atlantic and Indo-

618 Pacific realms, with the Tropical East Pacific (TEP) and Eastern Atlantic (EA) also 
619 defined regions (Fig. 4). However, unlike the results of Kulbicki et al. (2013), the TEP is

620 phylogenetically more similar to the rest of the Indo-Pacific than to the Atlantic. This

621 probably reflects the number of species that are found both in the large Indo-Pacific and

622 TEP realms (32 species in this analyses) and sister lineages presumably separated by the

623 East Pacific Barrier. Accounting for phylogenetic history has resulted in other dramatic

624 changes within the Indo-Pacific. Comparing the geographic schemes in Figs 1B and 4A

625 there is a large expansion of the region previously named the Central Indo-Pacific (CIP)

626 by Kulbicki et al. (2013). This cluster (red in Fig. 4A) now engulfs the majority of the

627 Indian and western Pacific Ocean, stretching from Madagascar and coastal India in the

628 west, to the Hawaiian Archipelago and Pitcairn Islands in the east. Ecoregions along the

629 East African coast are clustered together with the Red Sea locations. There is also a

630 cluster containing assemblages from the Ogasawara Islands in the northeastern Pacific

631 and Easter, Juan Fernández and Desventuradas Islands in the far eastern Pacific Ocean.

632 Clustering of Atlantic assemblages is similar to that found by Kulbicki et al. (2013), with

633 the exception of the Gulf of Guinea in the West African Coast standing out as separate to

634 the East Atlantic cluster (Fig. 4).

635 The expansion of the CIP to encompass the Indo-West Pacific (IWP hereafter) is

636 not unexpected. Previous schemes have outlined a large Indo-Pacific assemblage (Briggs

$637 \&$ Bowen, 2012) and even in the original analysis of Kulbicki et al. (2013) the entire

638 Indo-Pacific is characterized by very low internal dissimilarity. Accounting for

639 phylogenetic similarity among lineages in this analysis has captured the phylogenetic

640 connections between CIP and Central Pacific lineages. The outline of the Indo-Malay-

641 Philippine region (IMP, Fig. 1A; Carpenter \& Springer, 2005) previously united these

642 two provinces. Previous broad-scale biogeographic analyses have shown that the

643 diversity of fishes in the Central Pacific is derived from the expansion of lineages of IAA

644 origin (Cowman \& Bellwood, 2013a). More interesting is the extent of the incursion of

645 this new IWP cluster into the Indian Ocean to include Madagascar, Coastal India and Sri

646 Lanka - regions that have been considered closely associated with Indian Ocean, African

647 and Red Sea assemblages (Spalding et al., 2007; Keith et al., 2013; Mouillot et al., 2013;

648 Borsa et al., 2016). This appears to be the result of range expansion from the IAA to the 
west with wide lineage ranges and subsequent speciation reducing phylogenetic

650 dissimilarity (Fig. 5).

651 The clustering of islands separated by over 13,000 km is more curious.

652 Examination of the lineages found in the cluster containing the Ogasawara, Easter, Juan

653 Fernández and Desventuradas Islands (Fig. 5), shows that it is made up of widespread

654 lineages dispersed throughout the phylogeny, and by some small-range species that

655 appear to have evolved through peripheral isolation processes (cf. Hodge et al., 2012) on

656 these islands far from the biodiversity hotspot centre. This clustering may also reflect

657 some anti-tropical ranges found in several lineages sampled (e.g. Pseudolabrus,

658 Bodianus, Chromis; Randall, 1981) a pattern also seen in previous clustering analyses

659 (see supplemental material Kulbicki et al., 2013). In the Atlantic, the assemblage of

660 fishes found in the Gulf of Guinea stands apart from the rest of the East Atlantic cluster

661 with phylogenetically dispersed wide-ranging lineages and peripheral speciation

662 processes defining local assemblages differing from those at a regional scale (Fig. 5).

\section{4 (2) Tropical provinciality in the past}

665 Throughout the last 30 million years, shallow tropical marine habitats have undergone

666 massive reconfiguration. As a result, the distribution of and connections among

667 assemblages in the past may be quite different to what we see in the present day. By

668 incorporating estimates of ancestral ranges, we may be able to examine the changing

669 biogeographic structure of tropical reef fish assemblages. Fig. 6 illustrates the results of

670 phylogenetic lineage dissimilarity analyses at 3 million year intervals from 3 Ma to 27

671 Ma with corresponding dendrograms illustrating the clustering structure of 111 tropical

672 ecoregional assemblages.

673 Moving back in time, at $3 \mathrm{Ma}$, we see less phylogenetic separation of reef fish

674 assemblages either side of the Americas (Fig. 6A). The TEP is more closely aligned with

675 the West Atlantic (WA) assemblages than those in the Indo-Pacific, in contrast to the

676 present-day clustering analysis (Fig. 4). This points to a greater similarity of assemblages

677 either side of the Isthmus of Panama. Although many geminate pairs pre-date the final

678 closure of the Isthmus at 3.1 Ma (Lessios, 2008) the link between the TEP and the WA

679 here is likely due to the lack of subsequent lineage diversification in the last 3 million 
680 years within clades separated by the Isthmus. The link between these two regions is more 681 apparent at $6 \mathrm{Ma}$ (Fig. 6F) where a decline in phylogenetic dissimilarity between the WA 682 and TEP leads to a clustering of assemblages at Juan Fernández and Desventuradas 683 islands in the far eastern Pacific with assemblages on the East Brazilian Coast. Such 684 disjunct ranges (eastern Brazilian coast and Pacific islands) have previously been noted in 685 some clades of gastropods that lack coastal East Pacific congeners (Vermeij, 2001). 686 Given the complex geological and biological history of the Isthmus of Panama (Farris et 687 al., 2011; Bacon et al., 2015a; reviews by Leigh, O’Dea, \& Vermeij, 2014; Bagley \& 688 Johnson, 2014) extinction of marine lineages on both sides of the barrier may have led to 689 disjunct distributions of extant clades (Marko, Eytan \& Knowlton, 2015), biasing 690 phylogenetic dissimilarity estimates and the temporal signal of biogeographic processes.

691 Examples of such disjunct distributions linked to extinction on either side of the Isthmus 692 are the sparid species Archosargus pourtalesii found only in the Galapagos with its 693 closest relatives only in the Atlantic (McCosker, 1987), and the wrasse Halichoeres 694 rubrovirens from Trindade Island (South Atlantic) with its closest relative in the TEP 695 (Rocha, Pinheiro \& Gasparini, 2010).

696 Recent discussion on the age and evolutionary influence of the Isthmus of Panama 697 (Leigh et al., 2014; Bacon et al., 2015a; O'Dea et al., 2016) has highlighted its extended 698 biological history for some terrestrial and marine lineages, but cautions against the use of 699 incomplete and biased data sets (Lessios, 2015; Marko et al., 2015; but see Bacon et 700 al., 2015b). The analyses presented here are likely to be hindered by both undersampling 701 and extinction. However, from the assemblage perspective it is interesting that (with the 702 exception of Juan Fernández and Desventuradas islands) the TEP and the WA are 703 retained as separate, phylogenetically dissimilar clusters throughout the last 27 million 704 years, linked as sister-areas based on the presence/absence of particular genera (Floeter et 705 al., 2008) but not classified as phylogenetically similar in the present day by extant 706 assemblages. The influence of Indo-Pacific lineages can be seen in the clustering of 707 extant lineages (Fig. 4) reflecting those lineages that have been able to maintain genetic 708 connection across the East Pacific Barrier (Lessios \& Robertson, 2006). Between $27 \mathrm{Ma}$ 709 and $18 \mathrm{Ma}$ (Fig. 6F-I) the Caribbean assemblages show greater dissimilarity from other 710 Atlantic or Eastern Pacific ecoregions. This is likely a result of the high turnover of 
711 assemblages found there at this time and subsequent periods of extinction (Budd, 2000).

712 For example, the extinct fossil genera Eonaso (Tyler \& Sorbini, 1998) of Antigua,

713 Armbourgthurus of Iran (Tyler, 2000), Sorbinithurus of Monte Bolca, Italy (Tyler, 1999),

714 and Marosichthys of the Celebes in the west Pacific (Tyler, 1997) highlight an ancestral

715 pan-tropical distribution of the Nasinae (Acanthuridae) lineage, while its single living

716 genus Naso is restricted to the Indo-Pacific. The extinction of the three fossil genera

717 means these putative ancestral assemblage connections are not sampled in the deeper

718 parts of the phylogeny. Moving forward in time, it is the diversification and dispersal of

719 surviving lineages sampled in the phylogeny that influence assemblage similarity among

720 regions. Further insight into the deep-time affinity of tropical reef assemblages will

721 require the integration of the fossil and geological records of associated taxa.

722 On the far side of the Indo-Pacific there are significant fluctuations in

723 provinciality within the Indian Ocean region and its boundary with the IWP cluster (Fig.

724 6A-D). Prior to $3 \mathrm{Ma}$ the Red Sea was an independent province from the East African

725 coast cluster. At earlier time steps the East African coast cluster both includes and

726 excludes Madagascar and coastal India. At 12 Ma (Fig. 6D) the southeastern coast of

727 Africa (Delagoa, Agulhas Bank and Natal) forms a cluster dissimilar from the other

728 Indian Ocean assemblages. Between $27 \mathrm{Ma}$ and $15 \mathrm{Ma}$ an entire Indian Ocean cluster that

729 includes all Red Sea, East African coast, Madagascar and Indian coast assemblages

730 appears to be stable, with minor differences for some assemblages in the IWP cluster at

73118 Myr and 27 Myr (Fig. 6F,I).

732 Based on these temporal clustering analyses the Indian Ocean and IWP

733 assemblages are phylogenetically closer than they are to any TEP or Atlantic assemblage

734 from the $15 \mathrm{Ma}$ time step to the present. At $18 \mathrm{Ma}$, the IWP and TEP assemblages are

735 more phylogenetically similar to each other than they are to the Indian Ocean cluster

736 (Fig. 6F) and at $21 \mathrm{Ma}$ the Indian Ocean cluster is reconstructed to be more

737 phylogenetically similar to an East Atlantic cluster (Fig. 6G). A number of clades display

738 deep vicariance across an Atlantic/Indian Ocean divide (e.g. Holacanthus; Alva-

739 Campbell et al., 2010), but the timing of these vicariance events does not appear to be

740 concordant among fish families (Cowman \& Bellwood, 2013b). The biogeographic

741 clustering analysis described here suggests that this ancestral phylogenetic link between 
742 the Indian Ocean and East Atlantic could be a phylogenetic signal of the remnants of a

743 Tethys-like assemblage, at a time when the ancient seaway around northern Africa would

744 have supported a shallow-water reef habitat. Evidence from the fossil record of

745 foraminifera (Renema et al., 2008) highlights the Arabian region as a centre of paleo-

746 biodiversity for reef-associated taxa, an intermediate step in the eastward shift in marine

747 biodiversity at that time. For reef fishes, the earliest fossil records for many ancestral

748 forms lie in the Eocene deposits of Monte Bolca (Italy), a lagerstätten that contains both

749 Atlantic and Indo-Pacific taxa in an area close in proximity to the ancestral Tethyan

750 hotspot (Bellwood et al., 2016). At 27 Ma the signal of an ancient Tethyan province is

751 more apparent with the Indian Ocean cluster including reconstructed assemblages of the

752 Gulf of Guinea and the Sahelian upwelling ecoregion. The clustering of assemblages to

753 form a Tethyan province during this period not only highlights the effect of plate

754 tectonics on tropical reef biodiversity dynamics but also the phylogenetic history of reef

755 fish lineages (Leprieur et al., 2016b).

757 (3) Analytical considerations

758 Implementing the BayArea program for ancestral biogeographic reconstruction

759 allows a finer geographic resolution than previous methods and provides the opportunity

760 to examine dissimilarity clustering at various time points. However, there are a number of

761 limitations to the program in its current form that require care when interpreting results.

762 The reconstruction is based on a single phylogenetic reconstruction with no ability to

763 incorporate phylogenetic uncertainty or account for unsampled lineages. Inclusion of

764 unsampled lineages could alter the patterns presented here. Similarly, there is no way to

765 account for extinct lineages in the analysis, or use fossil data in the reconstruction, which

766 is permitted in other maximum likelihood approaches (Matzke, 2013). Furthermore, the

767 BayArea analysis is conducted under a static geological history, i.e. the dispersal model

768 cannot currently account for tectonic drift, sea-level changes, or the formation of barriers

769 (Landis et al., 2013). In particular, for reef-associated lineages the stability of reef habitat

770 through time has been an important factor influencing patterns of phylogenetic similarity

771 (Leprieur et al., 2016a). Our reconstruction did not treat land masses as dispersal barriers,

772 which may have resulted in reconstructing excessively wide ranges and unrealistic 
773 dispersal events. In the oldest time steps (Fig. 6H, I) the clustering of the eastern Pacific

774 islands within an Indian Ocean cluster appears to imply such possible analytical

775 limitation. However, even with this limitation the phylogenetic clustering of ancestral

776 ranges seems to provide a clear pattern of provincial rearrangement, with a signal of both

777 the closure of the Panama Isthmus and the Tethys seaway. This suggests that past and

778 present patterns of phylogenetic similarity can provide insight into the biogeographic

779 history of tropical assemblages.

\section{FUTURE DIRECTIONS}

782 The biodiversity of tropical reef systems has a complex pattern, with a history that has

783 been blurred by tectonic rearrangement and climatic shifts that have altered rates of

784 speciation, extinction, dispersal, and thus genetic connections among local and regional

785 assemblages. However, the combination of molecular phylogenies, fossil dating and

786 ancestral biogeographic estimation can allow us to trace the origins of biodiversity across

787 the globe. Here we show that including ancestral range reconstructions across many

788 discrete locations can result in a fine-scale biogeographic history on internal nodes of a

789 phylogenetic tree. This estimated biogeographic history, based entirely on present-day

790 ranges and the cladogenetic history of extant molecular lineages, can provide insight into

791 the historical connections among assemblages and the delineation of provinces over

792 shallow and deep timescales. The processes promoting marine endemism remain unclear,

793 both through lack of phylogenetic sampling and ambiguous definitions of an endemic

794 range. A more informative method of endemism classification based on range size

795 categories may provide an alternative approach to the study of local and regional

796 endemism (Borsa et al., 2016). Overall, a primary obstacle to overcome in future research

797 on the biogeographic history and biodiversity of reef (and many other) systems is the lack

798 of phylogenetic sampling and resolution of taxa that form these patterns.

799 There has been an incremental increase in the phylogenetic sampling of iconic

800 reef fish families (e.g. Chaetodontidae, Labridae, Pomacentridae; Cowman, 2014, and

801 references therein) while phylogenetic relationships in other reef-associated families are

802 only now beginning to receive significant phylogenetic attention (e.g. Blennidae,

803 Gobiidae; Hundt et al., 2014; Thacker, 2015). In general, fishes have a legacy of a 
804 significantly lower rate of phylogenetic resolution compared to other vertebrate lineages

805 in the last two decades (Thomson \& Shaffer, 2010). However, large-scale phylogenetic

806 efforts with a focus on the deeper relationships and systematics of fishes (Near et al.,

807 2012; Betancur-R. et al., 2013; Rabosky et al., 2013) are providing a framework to allow

808 macroevolutionary questions to be investigated at deeper timescales. For coral reefs in

809 particular, these 'top-down' approaches are revealing the early origins and tempo of

810 diversification of fish families on coral reefs (Price et al., 2014, 2015). The extant

811 biodiversity patterns we see on reefs today arose from the expansion of coral-dominated

812 reef habitat during the Miocene (23-5 Ma) and its influence on the diversification of its

813 associated fish fauna (Bellwood et al., 2015). Sampling and sequencing of genetic data

814 are needed from the 'bottom-up' to focus on filling the taxonomic gaps in species-level

815 phylogenies. New phylogenomic methods allowing the capture of hundreds of unlinked

816 loci (Faircloth et al., 2013) that can be used across evolutionary scales (Faircloth $e t$

817 al., 2012) promise to provide unparalleled ability to reconstruct species-level

818 phylogenies.

819 With complete species-level phylogenies, future research could include temporal

820 and biogeographic data to explore how lineages have diversified to form present-day

821 assemblages. The methods we outline here could be extended to incorporate a dynamic

822 geographic model whereby dispersal among locations changes through time to reflect

823 tectonic movement (Landis et al., 2013), or in the case of reef habitat the isolation or

824 collapse of habitat under different sea-level conditions (Pellissier et al., 2014). In addition

825 to describing patterns of provinciality and historic connections among assemblages, a

826 more in-depth understanding of how diversity has evolved would be gained by

827 quantifying rates of speciation, extinction and dispersal among locations. Rate estimation

828 and rate-shift analyses have been used to explore the tempo and mode of several groups

829 with reef affinities (Alfaro, Santini \& Brock, 2007; Cowman \& Bellwood, 2011; Litsios

830 et al., 2012). More recently, newly developed methods are being used to examine

831 variation in rates of speciation, extinction and dispersal (or transition) among species and

832 its correlation with geography or life history (Jetz et al., 2012; Rabosky et al., 2013;

833 Morlon, 2014). 
During the last 20-30 million years (Oligocene to Miocene epochs) we see the

835 functional development of reef fishes both in fossils (Bellwood et al., 2014) and

836 phylogenies (Cowman, Bellwood \& van Herwerden, 2009; Lobato et al., 2014). From a

837 functional aspect, high diversity in coral reef systems does not appear to beget functional

838 redundancy (Mouillot et al., 2014). With fewer species supporting critical but vulnerable

839 functional roles, it is important to understand how these functions have evolved along

840 lineages and whether those lineages are adequately protected under current conservation

841 efforts (Mouillot et al., 2016). From a marine conservation standpoint, it is critical to

842 consider the different types of biodiversity that can and should be protected. Although the

843 focus herein is the biogeographic origins of biodiversity in terms of species richness and

844 assemblage differences, an equally important aspect of coral reef fish evolution is in the

845 origins and distribution of functions critical for reef health. Life-history traits of reef

846 species and populations display interesting geographic patterns (Luiz et al., 2013; Selkoe

847 et al., 2016) that have yet to be fully explored for their evolutionary impact on past and

848 present assemblage patterns. Ancestral biogeography combining assessments of

849 functional evolution on coral reefs should remain an active area of research and

850 development in the future.

852 VII. CONCLUSIONS

853 (1) Defining important areas for biodiversity conservation in the marine tropics has

854 proved more difficult than in terrestrial systems. The IAA marine biodiversity hotspot is

855 recognized as an important repository of biodiversity for reef-associated fishes and other

856 organisms, but its origins still remain a matter of debate. For reef-associated fishes,

857 centres of total species richness are not concordant with centres of endemism. The origins

858 of complex patterns of endemic and wide-ranging species, richness gradients and

859 provincial assemblages can be explored using dated phylogenies combined with methods

860 to estimate ancestral biogeographic ranges.

861 (2) Although phylogenetic sampling of endemic lineages is generally low $(<20 \%)$, the

862 evolutionary origins of endemic-range species points to multiple processes acting in

863 concert to generate biodiversity across the Indo-Pacific. Most locations tend to have both

864 neo and paleo-endemic lineages, with a slight trend of older endemic taxa in higher 
865 proportions in more peripheral locations (Fig. 2). In relation to prevailing hypotheses

866 concerning the origins of Indo-Pacific biodiversity, temporal patterns of endemism

867 favour the IAA as a centre of survival, but its relative role in the origination of species

868 remains unclear due to undersampling of endemic lineages there.

869 (3) Accounting for measures of phylogenetic diversity in the delineation of present-day

870 assemblages across the tropics highlights the importance of connectivity among locations

871 and the impact of habitat stability during the Quaternary. Expansion of lineages from the

872 Central Indo-Pacific to adjacent locations has resulted in lower phylogenetic dissimilarity

873 across a larger Indo-West Pacific province, but coastal Africa and the Tropical East

874 Pacific remain separate clusters within the larger Indo-Pacific realm. Distant islands in

875 the Pacific, peripheral to the biodiversity hotspot are linked by phylogenetically distinct

876 lineages that may not taxonomically overlap. The basal split between the Atlantic and

877 Indo-Pacific highlights deep taxonomic divides and phylogenetic distance (Fig. 5).

878 (4) The past 30 million years has seen a massive reconfiguration in the provinciality of

879 reef fish assemblages. The cladogenetic history of several diverse reef fish families

880 displays fine-scale spatial arrangements that reflect both recent and deep-time alterations

881 in regional connectivity, isolation and lineage turnover. Phylogenetic dissimilarity

882 clustering of reconstructed assemblages highlights the influence of the Isthmus of

883 Panama land bridge and a deep-time connection between the Atlantic and Indian Ocean

884 assemblages via the ancient Tethys Seaway (Fig. 6), a pattern only seen previously in

885 fossils. Assemblages in the Caribbean display deep-time phylogenetic dissimilarity which

886 may reflect higher rates of extinction.

887 (5) In the absence of adequate fossil data, dated phylogenies and ancestral biogeographic

888 estimation may provide a glimpse at past assemblage differences. Molecular

889 phylogenetics and its utility as a tool to explore biogeographic and biodiversity patterns is

890 entering a new era. Cross-disciplinary research integrating phylogeny, palaeontology,

891 biogeography and functional assessments of reef-associated fishes will allow further

892 insight into how modern reef biodiversity was formed and what aspects are important for

893 its survival. The combination of genomic data sets and more sophisticated analytical

894 techniques will allow inference at the level of entire assemblages. Considering the dire

895 consequences facing coral reef biodiversity under a changing climate, future research 
896 focused on the evolution of coral reef biodiversity should aim to answer some important

897 questions: where has it come from, how is it maintained, and, where will it go?

\section{VIII. ACKNOWLEDGMENTS}

900 We thank M. Landis, and the M. Donoghue and T. Near lab groups at Yale for helpful

901 discussions. We thank F. Santini, B. Frédérich, P. Hundt, S. Klanten and M. Alfaro for

902 access to published phylogenetic trees for a number of reef-associated taxa. This work

903 took advantage of databases compiled for the GASPAR Program (M. Kulbicki). The

904 GASPAR program is part of the CESAB initiative financed by the Foundation pour la

905 Recherche en Biodiversité (FRB). S.R.F. was funded by CNPq- Brazil (305358/2015-4).

906 P.F.C. was funded by the Gaylord Donnelley Environmental Postdoctoral Fellowship

907 administered by the Yale Institute for Biospheric Studies (YIBS), and the Australian

908 Research Council Centre of Excellence for Coral Reef Studies.

910 IX. REFERENCES

911 Adams, C.G., Gentry, A.W. \& Whybrow, P.J. (1983). Dating of the terminal Tethyan

912 Event. Utrecht Micropaleontological Bulletins 30, 273-298.

913 Alfaro, M.E., Santini, F. \& BRock, C.D. (2007). Do reefs drive diversification in

914 marine teleosts? Evidence from the pufferfish and their allies (Order

915 Tetraodontiformes). Evolution 61, 2104-2126.

916 AlLEN, G.R. (2008). Conservation hotspots of biodiversity and endemism for Indo-

917 Pacific coral reef fishes. Aquatic Conservation: Marine and Freshwater Ecosystems

$918 \quad \mathbf{1 8}, 541-556$.

919 Alva-Campbell, Y., Floeter, S.R., Robertson, D.R., Bellwood, D.R. \& Bernardi,

920 G. (2010). Molecular phylogenetics and evolution of Holacanthus angelfishes

921 (Pomacanthidae). Molecular Phylogenetics and Evolution 56, 456-461.

922 Bacon, C.D., Silvestro, D., Jaramillo, C., Smith, B.T., Chakrabarty, P. \&

923 ANTONELLI, A. (2015a). Biological evidence supports an early and complex

924 emergence of the Isthmus of Panama. Proceedings of the National Academy of

925 Sciences 112, 6110-6115.

926 Bacon, C.D., Silvestro, D., Jaramillo, C., Smith, B.T., Chakrabarty, P. \& 
ANTONELLI, A. (2015b). Reply to Lessios and Marko et al.: Early and progressive migration across the Isthmus of Panama is robust to missing data and biases. Proceedings of the National Academy of Sciences 112, E5767-E5768.

BAgLey, J.C. \& Johnson, J.B. (2014) Phylogeography and biogeography of the lower Central American Neotropics: Diversification between two continents and between two seas. Biological Reviews 89, 767-790.

BARBER, P.H. \& BELLWOOD, D.R. (2005). Biodiversity hotspots: evolutionary origins of biodiversity in wrasses (Halichoeres: Labridae) in the Indo-Pacific and new world tropics. Molecular Phylogenetics and Evolution 35, 235-253.

Barber, P.H. \& MeYer, C.P. (2015). Pluralism explains diversity in the Coral Triangle. In Ecology of Fishes on Coral Reefs (ed C. MoRA), pp. 258-263. Cambridge University Press, Cambridge.

Bellwood, D.R., Goatley, C.H.R. \& Bellwood, O. (2016). The evolution of fishes and corals on reefs: form, function and interdependence. Biological Reviews. doi: $10.1111 /$ brv.12259.

Bellwood, D.R., Goatley, C.H.R., Brandl, S.J. \& Bellwood, O. (2014). Fifty million years of herbivory on coral reefs: fossils, fish and functional innovations. Proceedings of the Royal Society B: Biological Sciences 281, 20133046-20133046.

Bellwood, D.R., Goatley, C.H.R., Cowman, P.F. \& Bellwood, O. (2015). The evolution of fishes on coral reefs: fossils, phylogenies, and functions. In Ecology of Fishes on Coral Reefs (ed C. MorA), pp. 55-63. Cambridge University Press, Cambridge.

Bellwood, D.R., Hughes, T.P., Connolly, S.R. \& TAnneR, J. (2005). Environmental and geometric constraints on Indo-Pacific coral reef biodiversity. Ecology Letters $\mathbf{8}$, 643-651.

Bellwood, D.R., Hughes, T.P. (2001). Regional-scale assembly rules and biodiversity of coral reefs. Science 292, 1532-1535.

Bellwood, D.R. \& MeYer, C.P. (2009a). Endemism and evolution in the Coral Triangle: a call for clarity. Journal of Biogeography 36, 2010-2012.

Bellwood, D.R. \& MeYer, C.P. (2009b). Searching for heat in a marine biodiversity hotspot. Journal of Biogeography 36, 569-576. 
958 Bellwood, D.R., Renema, W. \& Rosen, B.R. (2012). Biodiversity hotspots, evolution and coral reef biogeography. In Biotic evolution and anvironmental change in southeast Asia (eds D. Gower, K. Johnson, J. RichARdson, B. Rosen, L. RUBer \& S. Williams), pp. 2-32. Cambridge Univ Press.

BELlWOOD, D.R. \& WAINWRIGHT, P.C. (2002). The history and biogeography of fishes on coral reefs. In Coral Reef Fishes. Dynamics and diversity in a complex ecosystem (ed P.F. SALE), pp. 5-32. Academic Press, San Diego.

Bender, M.G., Pie, M.R., Rezende, E.L., Mouillot, D. \& Floeter, S.R. (2013).

Betancur-R., R., Broughton, R.E., Wiley, E.O., Carpenter, K., López, J.A., Li, C., functional structure of Atlantic reef fish assemblages. Global Ecology and Holcroft, N.I., Arcila, D., Sanciangco, M., Cureton II, J.C., Zhang, F., Buser, T., CAmpbell, M.A., Ballesteros, J.A., RoA-VAron, A., Willis, S., ET Al. (2013) The Tree of Life and a New Classification of Bony Fishes. PLoS Currents Tree of Life 732988, 1-41.

Blackburn, T.M., Cassey, P. \& Gaston, K.J. (2006). Variations on a theme: sources of heterogeneity in the form of the interspecific relationship between abundance and distribution. Journal of Animal Ecology 75, 1426-1439.

Borsa, P., Durand, J.-D., Chen, W.-J., Hubert, N., Muths, D., Mou-Tham, G. \& KULBICKI, M. (2016). Comparative phylogeography of the western Indian Ocean reef fauna. Acta Oecologica 72, 72-86.

Bowen, B.W., Muss, A., RochA, L.A. \& GRAnt, W.S. (2006). Shallow mtDNA coalescence in Atlantic pygmy angelfishes (genus Centropyge) indicates a recent invasion from the Indian Ocean. Journal of Heredity 97, 1-12.

Bowen, B.W., Rocha, L. A., ToOnen, R.J. \& KarL, S. A. (2013). The origins of tropical marine biodiversity. Trends in Ecology \& Evolution 28, 359-366.

Bowman, D.M.J.S., Brown, G.K., Braby, M.F., Brown, J.R., CoOK, L.G., CrisP, M.D., Ford, F., Haberle, S., Hughes, J., Isagi, Y., Joseph, L., McBride, J., Nelson, G. \& LAdiges, P.Y. (2010). Biogeography of the Australian monsoon tropics. Journal of Biogeography 37, 201-216. 
989 BRIgGS, J.C. (2000). Centrifugal speciation and centres of origin. Journal of

$990 \quad$ Biogeography 27, 1183-1188.

991 BRIGgS, J.C. (2009). Diversity, endemism and evolution in the Coral Triangle. Journal of 992 Biogeography 36, 2008-2010.

993 BRIGGs, J.C. \& BowEN, B.W. (2012). A realignment of marine biogeographic provinces 994 with particular reference to fish distributions. Journal of Biogeography 39, 12-30.

995 BRiggs, J.C. \& BowEN, B.W. (2013). Marine shelf habitat: biogeography and evolution. 996 Journal of Biogeography 40, 1023-1035.

997 BudD, A. F. (2000) Diversity and extinction in the Cenozoic history of Caribbean reefs. $998 \quad$ Coral Reefs 19, 25-35.

999 Carpenter, K.E., Barber, P.H., Crandall, E.D., Ablan-Lagman, M.C. A., 1000 Ambariyanto, Mahardika, G.N., Manjaji-Matsumoto, B.M., Juinio-Meñez, 1001 M.A., Santos, M.D., Starger, C.J. \& Toha, A.H. A. (2011). Comparative 1002 phylogeography of the coral triangle and implications for marine management. 1003 Journal of Marine Biology 2011, 1-14.

1004 CARPENTER, K.E. \& SPRINGER, V.G. (2005). The center of the center of marine shore fish 1005 biodiversity: the Philippine Islands. Environmental Biology of Fishes 72, 467-480.

1006 Choat, J.H., Klanten, O.S., Van Herwerden, L., Robertson, D.R. \& Clements, 1007 K.D. (2012). Patterns and processes in the evolutionary history of parrotfishes 1008 (Family Labridae). Biological Journal of the Linnean Society 107, 529-557.

1009 CoATES, A.G. (1973). Cretaceous tethyan coral-rudist biogeography related to the 1010 evolution of the Atlantic Ocean. Special Papers in Palaeontology 12, 169-174.

1011 CoAtes, A.G. \& OBAndo, J.A. (1996). The geologic evolution of the Central American 1012 Isthmus. In Evolution and Environment in Tropical America pp. 21-56. University 1013 of Chicago Press, Chicago.

1014 CONNOLLY, S.R. (2005). Process-based models of species distributions and the mid1015 domain effect. The American Naturalist 166, 1-11.

1016 Connolly, S.R., Bellwood, D.R. \& Hughes, T.P. (2003). Indo-pacific biodiversity of 1017 coral reefs: deviations from a mid-domain model. Ecology 84, 2178-2190.

1018 Cowman, P.F. (2014). Historical factors that have shaped the evolution of tropical reef 1019 fishes: a review of phylogenies, biogeography, and remaining questions. Frontiers 
in Genetics 5, 1-15.

COWMAN, P.F. \& BELLWOOD, D.R. (2011). Coral reefs as drivers of cladogenesis: expanding coral reefs, cryptic extinction events, and the development of biodiversity hotspots. Journal of Evolutionary Biology 24, 2543-2562.

CowmAn, P.F. \& BELLWOOD, D.R. (2013a). The historical biogeography of coral reef fishes: global patterns of origination and dispersal. Journal of Biogeography $\mathbf{4 0}$, $209-224$.

CowmAn, P.F. \& BeLLwood, D.R. (2013b). Vicariance across major marine biogeographic barriers: temporal concordance and the relative intensity of hard versus soft barriers. Proceedings of the Royal Society B: Biological Sciences 280 , 20131541-20131541.

Cowman, P.F., Bellwood, D.R. \& van Herwerden, L. (2009). Dating the evolutionary origins of wrasse lineages (Labridae) and the rise of trophic novelty on coral reefs. Molecular Phylogenetics and Evolution 52, 621-631.

Coyne, J.A. \& OrR, H.A. (2004). Speciation. Sunderland, MA. Sinauer Associates, Inc.

Craig, M., Eble, J., Bowen, B. \& Robertson, D. (2007). High genetic connectivity across the Indian and Pacific Oceans in the reef fish Myripristis berndti (Holocentridae). Marine Ecology Progress Series 334, 245-254.

DeMartini, E. \& Friedlander, A. (2004). Spatial patterns of endemism in shallowwater reef fish populations of the Northwestern Hawaiian Islands. Marine Ecology Progress Series 271, 281-296.

DiBattista, J.D., Howard ChOAt, J., Gaither, M.R., Hobbs, J.-P. A, LoZANO-Cortés, D.F., Myers, R.F., Paulay, G., Rocha, L.A., Toonen, R.J., Westneat, M.W. \& BERUMEN, M.L. (2016a). On the origin of endemic species in the Red Sea. Journal of Biogeography 43, 13-30.

DiBattista, J.D., Roberts, M.B., Bouwmeester, J., Bowen, B.W., Coker, D.J., Lozano-Cortés, D.F., Howard ChoAt, J., Gaither, M.R., Hobbs, J.-P.A., Khalil, M.T., Kochzius, M., Myers, R.F., Paulay, G., Robitzch, V.S.N., SaenzAgUdelo, P., ET AL. (2016b) A review of contemporary patterns of endemism for shallow water reef fauna in the Red Sea. Journal of Biogeography 43, 423-439.

Dornburg, A., Moore, J., Beaulieu, J.M., Eytan, R.I. \& Near, T.J. (2015). The 
1051

1052

1053

1054

1055

1056

1057

1058

1059

1060

1061

1062

1063

1064

1065

1066

1067

1068

1069

1070

1071

1072

1073

1074

1075

1076

1077

1078

1079

1080

1081

impact of shifts in marine biodiversity hotspots on patterns of range evolution: Evidence from the Holocentridae (squirrelfishes and soldierfishes). Evolution 69, $146-161$.

EKMAN, S. (1953). Zoogeography of the sea. Sidgwick \& Jackson, London.

Evans, S.M., McKenna, C., Simpson, S.D., Tournois, J. \& Genner, M.J. (2016). Patterns of species range evolution in Indo-Pacific reef assemblages reveal the Coral Triangle as a net source of transoceanic diversity. Biology Letters 12, 20160090. FAIRCLOTH, B.C., McCoRMACK, J.E., CraWford, N.G., HARVEY, M.G., BRUMFIELD, R.T. \& GLENN, T.C. (2012). Ultraconserved elements anchor thousands of genetic markers spanning multiple evolutionary timescales. Systematic Biology 61, 717726.

Faircloth, B.C., Sorenson, L., Santini, F. \& Alfaro, M.E. (2013). A phylogenomic perspective on the radiation of ray-finned fishes based upon targeted sequencing of ultraconserved elements (UCEs). PLoS ONE 8, e65923.

Farris, D.W., Jaramillo, C., Bayona, G., Restrepo-Moreno, S. A., Montes, C., Cardona, A., Mora, A., Speakman, R.J., Glascock, M.D. \& Valencia, V. (2011). Fracturing of the Panamanian Isthmus during initial collision with South America. Geology 39, 1007-1010.

Floeter, S.R., Rocha, L.A., Robertson, D.R., Joyeux, J.C., SMith-VANiz, W.F., Wirtz, P., Edwards, A. J., Barreiros, J.P., Ferreira, C.E.L., Gasparini, J.L., Brito, A., Falcón, J.M., Bowen, B.W. \& Bernardi, G. (2008). Atlantic reef fish biogeography and evolution. Journal of Biogeography 35, 22-47.

Frédérich, B., Sorenson, L., Santini, F., Slater, G.J. \& Alfaro, M.E. (2013). Iterative ecological radiation and convergence during the evolutionary history of damselfishes (Pomacentridae). The American Naturalist 181, 94-113.

Friedlander, A.M., Ballesteros, E., Caselle, J.E., Gaymer, C.F., Palma, A.T., Petit, I., Varas, E., Muñoz Wilson, A. \& Sala, E. (2016). Marine biodiversity in Juan Fernández and Desventuradas Islands, Chile: global endemism hotspots. PLos One 11, e0145059.

FRIEDMAN, M. (2010). Explosive morphological diversification of spiny-finned teleost fishes in the aftermath of the end-Cretaceous extinction. Proceedings of the Royal 
1082

1083

1084

1085

1086

1087

1088

1089

1090

1091

1092

1093

1094

1095

1096

1097

1098

1099

1100

1101

1102

1103

1104

1105

1106

1107

1108

1109

1110

1111

1112

Society B: Biological Sciences 277, 1675-1683.

GAITHER, M.R. \& RochA, L. A. (2013). Origins of species richness in the Indo-MalayPhilippine biodiversity hotspot: evidence for the centre of overlap hypothesis. Journal of Biogeography 40, 1638-1648.

Gaither, M.R., Toonen, R.J., Robertson, D.R., Planes, S. \& Bowen, B.W. (2009). Genetic evaluation of marine biogeographical barriers: Perspectives from two widespread Indo-Pacific snappers (Lutjanus kasmira and Lutjanus fulvus). Journal of Biogeography 37, 133-147.

GAstOn, K.J. (2003). The how and why of biodiversity. Nature 421, 900-901.

Goatley, C.H.R., Bellwood, D.R. \& Bellwood, O. (2010). Fishes on coral reefs: changing roles over the past 240 million years. Paleobiology 36, 415-427.

Halas, D. \& Winterbottom, R. (2009). A phylogenetic test of multiple proposals for the origins of the East Indies coral reef biota. Journal of Biogeography 36, 18471860.

Hallam, A. (1973). Distributional patterns in contemporary terrestrial and marine animals. In Organisms and Continents Through Time (ed N.F. HugHES), pp. 93105. Special Papers in Palaeontology.

Harzhauser, M., Kroh, A., Mandic, O., Piller, W.E., Göhlich, U., Reuter, M. \& BERNING, B. (2007). Biogeographic responses to geodynamics: a key study all around the Oligo-Miocene Tethyan Seaway. Zoologischer Anzeiger - A Journal of Comparative Zoology 246, 241-256.

Hattab, T., Albouy, C., Ben Rais Lasram, F., Le Loc'H, F., Guilhaumon, F. \& LEPRIEUR, F. (2015). A biogeographical regionalization of coastal Mediterranean fishes. Journal of Biogeography 42, 1336-1348.

HeCK, K.L. \& MCCOY, E.D. (1978). Long-distance dispersal and the reef-building corals of the Eastern Pacific. Marine Biology 48, 349-356.

Hillebrand, H. (2004). On the generality of the latitudinal diversity gradient. The American Naturalist 163, 192-211.

Hodge, J.R., ReAd, C.I., Bellwood, D.R. \& VAn Herwerden, L. (2013). Evolution of sympatric species: a case study of the coral reef fish genus Pomacanthus (Pomacanthidae). Journal of Biogeography 40, 1676-1687. 
1113 Hodge, J.R., Read, C.I., van Herwerden, L. \& Bellwood, D.R. (2012). The role of 1114 peripheral endemism in species diversification: Evidence from the coral reef fish 1115 genus Anampses (Family: Labridae). Molecular Phylogenetics and Evolution 62, $1116 \quad 653-663$.

1117 Hodge, J.R., van Herwerden, L. \& Bellwood, D.R. (2014). Temporal evolution of 1118 coral reef fishes: global patterns and disparity in isolated locations. Journal of 1119 Biogeography 41, 2115-2127.

1120 Hoeksema, B.W. (2007). Delineation of the Indo-Malayan Centre of Maximum Marine 1121 Biodiversity: The Coral Triangle. In Biogeography, time, and place: Distributions, 1122 Barriers, and Islands (ed W. RENEMA), pp. 117-178.

1123 Horne, J.B., van Herwerden, L., ChoAt, J.H. \& Robertson, D.R. (2008). High

1124 population connectivity across the Indo-Pacific: congruent lack of phylogeographic 1125 structure in three reef fish congeners. Molecular Phylogenetics and Evolution 49, $1126 \quad 629-638$.

1127 Hubert, N., Meyer, C.P., Bruggemann, H.J., Guérin, F., Komeno, R.J.L., Espiau, B., 1128 Causse, R., Williams, J.T. \& Planes, S. (2012). Cryptic diversity in Indo-Pacific 1129 coral-reef fishes revealed by DNA-barcoding provides new support to the centre-of$1130 \quad$ overlap hypothesis. PLoS ONE 7, e28987.

1131 Hughes, T.P., Bellwood, D.R. \& ConNolly, S.R. (2002). Biodiversity hotspots, 1132 centres of endemicity, and the conservation of coral reefs. Ecology Letters 5, 7751133784.

1134 Hughes, T.P., Bellwood, D.R., Connolly, S.R., Cornell, H. V. \& Karlson, R.H.

1135 (2014). Double jeopardy and global extinction risk in corals and reef fishes. Current 1136 Biology 24, 2946-2951.

1137 Hughes, T.P., DAY, J.C. \& BRodie, J. (2015). Securing the future of the Great Barrier 1138 Reef. Nature Climate Change 5, 508-511.

1139 Hundt, P.J., IglÉsias, S.P., Hoey, A.S. \& SimOns, A.M. (2014). A multilocus molecular 1140 phylogeny of combtooth blennies (Percomorpha: Blennioidei: Blenniidae): Multiple 1141 invasions of intertidal habitats. Molecular Phylogenetics and Evolution 70, 47-56.

1142 JablonsKi, D., Roy, K. \& VAlentine, J.W. (2006). Out of the tropics: Evolutionary 1143 dynamics of the latitudinal diversity gradient. Science 314, 102-106. 
1144 Jetz, W., Thomas, G.H., Joy, J.B., Hartmann, K. \& Mooers, A O. (2012). The global

1145 diversity of birds in space and time. Nature 491, 444-448.

1146 Kamp, P., Waghorn, D., Nelson, C. \& ZeAland, N. (1990). Late Eocene-Early

1147 Oligocene integrated isotope stratigraphy and biostratigraphy for paleoshelf

1148 sequences in southern Australia: paleoceanographic implications. Palaeogeography,

1149 Palaeoclimatology, Palaeoecology 80, 311-323.

1150 Keith, S.A., Baird, A.H., Hughes, T.P., Madin, J.S. \& Connolly, S.R. (2013). Faunal

1151 breaks and species composition of Indo-Pacific corals: the role of plate tectonics,

1152 environment and habitat distribution. Proceedings of the Royal Society B: Biological

$1153 \quad$ Sciences 280, 20130818.

1154 Kelley, L. A, GARDNER, S.P. \& SutClifFe, M.J. (1997). An automated approach for

1155 defining core atoms and domains in an ensemble of NMR-derived protein structures.

1156 Protein Engineering Design and Selection 10, 737-741.

1157 Kiessling, W., Simpson, C. \& Foote, M. (2010). Reefs as cradles of evolution and

1158 sources of biodiversity in the Phanerozoic. Science 327, 196-198.

1159 Koleff, P., Gaston, K.J. \& Lennon, J.J. (2003). Measuring beta diversity for presence-

$1160 \quad$ absence data. Journal of Animal Ecology 72, 367-382.

1161 KoOl, J.T., PAris, C.B., BArber, P.H. \& Cowen, R.K. (2011). Connectivity and the

1162 development of population genetic structure in Indo-West Pacific coral reef

1163 communities. Global Ecology and Biogeography 20, 695-706.

1164 KREFT, H. \& JETZ, W. (2010). A framework for delineating biogeographical regions

1165 based on species distributions. Journal of Biogeography 37, 2029-2053.

1166 Kulbicki, M., Parravicini, V., Bellwood, D.R., Arias-GonzÀlez, E., Chabanet, P.,

1167 Floeter, S.R., Friedlander, A., McPherson, J., Myers, R.E., Vigliola, L. \&

1168 Mouillot, D. (2013). Global biogeography of reef fishes: a hierarchical

1169 quantitative delineation of regions. PloS one $\mathbf{8}$, e81847.

1170 Kulbicki, M., Vigliola, L., Wantiez, L., Hubert, N., Floeter, S.R. \& Myers, R.F.

1171 (2014). Biogeography of butterflyfishes: a global model for reef fishes? In Biology

1172 of Butterflyfishes (eds M.S. Pratchett, M.L. BERUMEN \& B.G. KAPOOR), pp. 70-

1173 106. CRC Press.

1174 LADD, H.S. (1960). Origin of the Pacific island molluscan fauna. American Journal of 
$1175 \quad$ Science 258-A, 137-150.

1176 Landis, M.J., MatzKe, N.J., Moore, B.R. \& HuelsenbeCK, J.P. (2013). Bayesian

1177 analysis of biogeography when the number of areas is large. Systematic Biology 62,

$1178 \quad 789-804$.

1179 Leigh, E.G., O’DEA, A. \& VermeIJ, G.J. (2014) Historical biogeography of the Isthmus

1180 of Panama. Biological reviews of the Cambridge Philosophical Society 89, 148-172.

1181 Leprieur, F., Albouy, C., De Bortoli, J., Cowman, P.F., Bellwood, D.R. \&

1182 MouILLOT, D. (2012). Quantifying phylogenetic beta diversity: distinguishing

1183 between 'true' turnover of lineages and phylogenetic diversity gradients. PLOS ONE

11847 7, e42760.

1185 Leprieur, F., Colosio, S., Descombes, P., Parravicini, V., Kulbicki, M., Cowman,

1186 P.F., Bellwood, D.R., Mouillot, D. \& Pellissier, L. (2016a). Historical and

1187 contemporary determinants of global phylogenetic structure in tropical reef fish

1188 faunas. Ecography 39, 825-835.

1189 Leprieur, F., Descombes, P., Gaboriau, T., Cowman, P.F., Parravicini, V.,

1190 Kulbicki, M., Melián, C.J., de Santana, C.N., Heine, C., Mouillot, D.,

1191 Bellwood, D.R. \& Pellissier, L. (2016b). Plate tectonics drive tropical reef

$1192 \quad$ biodiversity dynamics. Nature Communications 7, 11461.

1193 LEssios, H.A. (2008) The great American schism: divergence of marine organisms after

1194 the rise of the Central American Isthmus. Annual Review of Ecology Evolution and

1195 Systematics 39, 63-91.

1196 LEssios, H.A. (2015). Appearance of an early closure of the Isthmus of Panama is the

1197 product of biased inclusion of data in the metaanalysis. Proceedings of the National 1198 Academy of Sciences 112, E5765-E5765.

1199 Lessios, H.A. \& ROBERTSON, D.R. (2006) Crossing the impassable: genetic connections

1200 in 20 reef fishes across the eastern Pacific barrier. Proceedings of the Royal Society

1201 of London B: Biological Sciences 273, 2201-2208.

1202 Levy, A., Wirtz, P., Floeter, S.R. \& Almada, V.C. (2011). The Lusitania Province as

1203 a center of diversification: the phylogeny of the genus Microlipophrys (Pisces:

1204 Blenniidae). Molecular Phylogenetics and Evolution 58, 409-413.

1205 Liggins, L., Booth, D.J., Figueira, W.F., Treml, E. A, Tonk, L., Ridgway, T., Harris, 
Litsios, G., Pearman, P.B., Lanterbecq, D., Tolou, N. \& Salamin, N. (2014). The radiation of the clownfishes has two geographical replicates. Journal of

1212 Litsios, G., Sims, C. A, Wüest, R.O., Pearman, P.B., Zimmermann, N.E. \& Salamin, 1213 N. (2012). Mutualism with sea anemones triggered the adaptive radiation of 1214 clownfishes. BMC Evolutionary Biology 12, 212.

1215 Lobato, F.L., Barneche, D.R., Siqueira, A.C., Liedke, A.M.R., Lindner, A., Pie, 1216 M.R., Bellwood, D.R. \& Floeter, S.R. (2014). Diet and diversification in the 1217 evolution of coral reef fishes. PLOS ONE 9, e102094.

1218 Luiz, O.J., Allen, A. P., Robertson, D.R., Floeter, S.R., Kulbicki, M., Vigliola, L., 1219 BECHELER, R. \& MADIN, J.S. (2013). Adult and larval traits as determinants of geographic range size among tropical reef fishes. Proceedings of the National Academy of Sciences 110, 16498-16502.

Marko, P.B., Eytan, R.I. \& KnOWlton, N. (2015). Do large molecular sequence divergences imply an early closure of the Isthmus of Panama? Proceedings of the National Academy of Sciences 112, E5766-E5766.

MAtZKe, N.J. (2013). Probabilistic historical biogeography: new models for founderevent speciation, imperfect detection, and fossils allow improved accuracy and model-testing. Frontiers of Biogeography 5, 242-248.

McCosker, J.E. (1987). The fishes of the Galapagos Islands. Oceanus 30, 28-32.

MCCOY, E.D. \& HECK, K.L. (1976). Biogeography of corals, seagrasses, and mangroves: an alternative to the center of origin concept. Systematic Zoology 25, 201.

McKenna, D.D. \& FARRELL, B.D. (2006). Tropical forests are both evolutionary cradles and museums of leaf beetle diversity. Proceedings of the National Academy of Sciences of the United States of America 103, 10947-10951.

Mittermeier, R.A., Robles, G.P., Hoffmann, M., Pilgrim, J., Brooks, T., Mittermeier, C.G., Lamoreux, J. \& Da Fonseca, G.A.B. (2005). Hotspots Revisited: Earth's Biologically Richest and Most Endangered Terrestrial 
Ecosystems. Conservation International, Washington, DC.

Mittermeier, R.A., Turner, W.R., Larsen, F.W., Brooks, T.M. \& Gascon, C. (2011). Biodiversity Hotspots. Springer Berlin Heidelberg.

Montes, C., Cardona, A., Jaramillo, C., Pardo, A., Silva, J.C., Valencia, V., Ayala, C., Pérez-Angel, L.C., Rodriguez-Parra, L. A, Ramirez, V. \& Niño, H. (2015). Middle Miocene closure of the Central American Seaway. Science 348, $226-229$.

Mora, C., Chittaro, P.M., Sale, P.F., Kritzer, J.P., Ludsin, S. A. \& Africa, S. (2003). Patterns and processes in reef fish diversity. Nature 421, 933-936.

Mora, C., TitTensor, D.P. \& Myers, R. A (2008). The completeness of taxonomic inventories for describing the global diversity and distribution of marine fishes. Proceedings of the Royal Society B: Biological Sciences 275, 149-155.

Moreau, C.S. \& BELL, C.D. (2013). Testing the museum versus cradle tropical biological diversity hypothesis: Phylogeny, diversification, and ancestral biogeographic range evolution of the ants. Evolution 67, 2240-2257.

Morlon, H. (2014). Phylogenetic approaches for studying diversification. Ecology Letters 17, 508-525.

Mouillot, D., De Bortoli, J., Leprieur, F., Parravicini, V., Kulbicki, M. \& BELlwoOd, D.R. (2013). The challenge of delineating biogeographical regions: nestedness matters for Indo-Pacific coral reef fishes. Journal of Biogeography $\mathbf{4 0}$, $2228-2237$.

Mouillot, D., Parravicini, V., Bellwood, D.R., Leprieur, F., Huang, D., Cowman, P.F., Albouy, C., Hughes, T.P., Thuiller, W. \& Guilhaumon, F. (2016). Global marine protected areas do not secure the evolutionary history of tropical corals and fishes. Nature Communications 7, 10359.

Mouillot, D., Villeger, S., Parravicini, V., Kulbicki, M., Arias-GonZalez, J.E., Bender, M., Chabanet, P., Floeter, S.R., Friedlander, A., Vigliola, L. \& BELLWOOD, D.R. (2014). Functional over-redundancy and high functional vulnerability in global fish faunas on tropical reefs. Proceedings of the National Academy of Sciences 111, 13757-13762.

Myers, N. (1988). Threatened biotas: 'hot spots' in tropical forests. The 
Environmentalist 8, 187-208.

Myers, N., Mittermeier, R.A., Mittermeier, C.G., DA Fonseca, G.A. \& Kent, J. (2000). Biodiversity hotspots for conservation priorities. Nature 403, 853-858.

Near, T.J., Eytan, R.I., Dornburg, A., Kuhn, K.L., Moore, J. A, Davis, M.P., WAinwright, P.C., Friedman, M. \& SMITh, W.L. (2012). Resolution of ray-finned fish phylogeny and timing of diversification. Proceedings of the National Academy of Sciences 109, 13698-13703.

O’Dea, A., Lessios, H.A., CoAtes, A.G., Eytan, R.I., Restrepo-Moreno, S.A., Cione, A.L., Collins, L.S., DE QueIroz, A., Farris, D.W., Norris, R.D., Stallard, R.F., Woodburne, M.O., Aguilera, O., Aubry, M.-P., Berggren, W.A., et Al. (2016) Formation of the Isthmus of Panama. Science Advances 2, e1600883.

Olson, D.M., Dinerstein, E., Wikramanayake, E.D., Burgess, N.D., Powell, G.V.N., Underwood, E.C., D’Amico, J.A., Itoua, I., Strand, H.E., Morrison, J.C., Loucks, C.J., Allnutt, T.F., Ricketts, T.H., Kura, Y., LamoreuX, J.F., Wettengel, W.W., Hedao, P. \& Kassem, K.R. (2001). Terrestrial ecoregions of the world: a new map of life on Earth. BioScience 51, 933.

Orme, C.D.L., Davies, R.G., Burgess, M., Eigenbrod, F., Pickup, N., Olson, V. A, Webster, A.J., Ding, T.-S., Rasmussen, P.C., Ridgely, R.S., Stattersfield, A.J., Bennett, P.M., Blackburn, T.M., Gaston, K.J. \& Owens, I.P.F. (2005). Global hotspots of species richness are not congruent with endemism or threat. Nature 436, $1016-1019$.

Parravicini, V., Kulbicki, M., Bellwood, D.R., Friedlander, A. M., AriasGonzalez, J.E., Chabanet, P., Floeter, S.R., Myers, R., Vigliola, L., D’Agata, S. \& Mouillot, D. (2013). Global patterns and predictors of tropical reef fish species richness. Ecography 36, 1254-1262.

Parravicini, V., Villéger, S., McClanahan, T.R., Arias-GonzÁlez, J.E., Bellwood, D.R., Belmaker, J., Chabanet, P., Floeter, S.R., Friedlander, A.M., Guilhaumon, F., Vigliola, L., Kulbicki, M. \& Mouillot, D. (2014). Global mismatch between species richness and vulnerability of reef fish assemblages. Ecology Letters 17, 1101-1110.

Pellissier, L., LePrieur, F., Parravicini, V., Cowman, P.F., Kulbicki, M., Litsios, 
G., Olsen, S.M., WisZ, M.S., Bellwood, D.R. \& Mouillot, D. (2014). Quaternary coral reef refugia preserved fish diversity. Science 344, 1016-1019.

Pimm, S.L., Jenkins, C.N., Abell, R., Brooks, T.M., GitTleman, J.L., JopPA, L.N., Raven, P.H., RoberTs, C.M. \& SeXton, J.O. (2014). The biodiversity of species and their rates of extinction, distribution, and protection. Science 344, 12467521246752.

PotTs, D.C. (1985). Sea level fluctuations and speciation in Scleractina. In Proceedings of the Fifth International Coral Reef Congress pp. 127-132.

Price, S.A., Claverie, T., Near, T.J. \& Wainwright, P.C. (2015). Phylogenetic insights into the history and diversification of fishes on reefs. Coral Reefs 34, 9971009.

Price, S.A., Schmitz, L., Oufiero, C.E., Eytan, R.I., Dornburg, A., Smith, W.L., Friedman, M., Near, T.J. \& Wainwright, P.C. (2014). Two waves of colonization straddling the K-Pg boundary formed the modern reef fish fauna. Proceedings of the Royal Society B: Biological Sciences 281, 20140321.

PyBus, O.G. \& HARVEY, P.H. (2000). Testing macro-evolutionary models using incomplete molecular phylogenies. Proceedings of the Royal Society B: Biological Sciences 267, 2267-2272.

Rabosky, D.L., Santini, F., Eastman, J., Smith, S. A., Sidlauskas, B., Chang, J. \& ALFARO, M.E. (2013). Rates of speciation and morphological evolution are correlated across the largest vertebrate radiation. Nature Communications 4, 1-8.

RANDALL, J.E. (1981). Examples of anti-tropical and anti-equatorial distribution of IndoWest-Pacific fishes. Pacific Sciences 35, 197-209.

RANDALL, J.E. (1998). Zoogeography of shore fishes of the Indo-Pacific region. Zoological Studies 37, 227-268.

RANDALL, J.E. (2007). Reef and shore fishes of the Hawaiian Islands. Sea Grant College Program, University of Hawai'i Press.

RANDALL, J.E. \& CEA, A. (2011). Shore fishes of Easter Island. University of Hawaii Press, Honolulu.

Ree, R.H., Moore, B.R., Webi, C.O. \& Donoghue, M.J. (2005). A likelihood framework for inferring the evolution of geographic range on phylogenetic trees. 
Evolution 59, 2299-2311.

REE, R.H. \& SMITH, S.A (2008). Maximum likelihood inference of geographic range evolution by dispersal, local extinction, and cladogenesis. Systematic Biology 57, 414.

Renema, W., Bellwood, D.R., Braga, J.C., Bromfield, K., Hall, R., Johnson, K.G., Lunt, P., Meyer, C.P., McMonagle, L.B., Morley, R.J., O’DeA, A., TodD, J.A., Wesselingh, F.P., Wilson, M.E.J. \& PANDOLFI, J.M. (2008). Hopping hotspots: global shifts in marine biodiversity. Science 321, 654-657.

Roberts, C.M., McClean, C.J., Veron, J.E.N., Hawkins, J.P., Allen, G.R., McAllister, D.E., Mittermeier, C.G., Schueler, F.W., Spalding, M., Wells, F., Vynne, C. \& Werner, T.B. (2002). Marine biodiversity hotspots and conservation priorities for tropical reefs. Science 295, 1280-1284.

Robertson, D.R. \& CRAMER, K.L. (2014). Defining and dividing the Greater Caribbean: insights from the biogeography of shorefishes. PloS One 9, e102918.

Rocha, L.A., PINHeIRo, H.T. \& GASPARINI, J.L. (2010). Description of Halichoeres rubrovirens, a new species of wrasse (Labridae: Perciformes) from the Trindade and Martin Vaz Island group, southeastern Brazil, with a preliminary mtDNA molecular phylogeny of New World Halichoeres. Zootaxa 2422, 22-30.

Rocha, L.A., Robertson, D.R., Rocha, C.R., VAn TAssell, J.L., CRAig, M.T. \& BoweN, B.W. (2005a). Recent invasion of the tropical Atlantic by an Indo-Pacific coral reef fish. Molecular Ecology 14, 3921-3928.

Rocha, L.A., Robertson, D.R., Roman, J. \& Bowen, B.W. (2005b). Ecological speciation in tropical reef fishes. Proceedings of the Royal Society B: Biological Sciences 272, 573-579.

RoGL (1998). Palaeogeographic considerations for Mediterranean and Paratethys seaways (Oligocene to Miocene). Annalen des Naturhistorischen Museums in Wien 99, 279-310.

Rosen, B.R. (1984). Reef coral biogeography and climate through the Late Cainozoic: just islands in the sun or a critical pattern of islands? Geological Journal. Special issue, 201-262.

Santini, F., Carnevale, G. \& Sorenson, L. (2014). First multi-locus timetree of 
1361

1362

1363

1364

1365

1366

1367

1368

1369

1370

1371

1372

1373

1374

1375

1376

1377

1378

1379

1380

1381

1382

1383

1384

1385

1386

1387

1388

1389

1390

1391

seabreams and porgies (Percomorpha: Sparidae). Italian Journal of Zoology 81, 5571.

Santini, F., Sorenson, L., Marcroft, T., Dornburg, A. \& Alfaro, M.E. (2013). A multilocus molecular phylogeny of boxfishes (Aracanidae, Ostraciidae; Tetraodontiformes). Molecular Phylogenetics and Evolution 66, 153-160.

Selkoe, K.A., Gaggiotti, O.E., Treml, E.A., Wren, J.L.K., Donovan, M.K. \& ToOnEN, R.J. (2016). The DNA of coral reef biodiversity: predicting and protecting genetic diversity of reef assemblages. Proceedings of the Royal Society B: Biological Sciences 283, 20160354.

Sorenson, L., SAntini, F. \& Alfaro, M.E. (2014). The effect of habitat on modern shark diversification. Journal of Evolutionary Biology 27, 1536-1548.

Sorenson, L., Santini, F., Carnevale, G. \& Alfaro, M.E. (2013). A multi-locus timetree of surgeonfishes (Acanthuridae, Percomorpha), with revised family taxonomy. Molecular phylogenetics and evolution 68, 150-160. Elsevier Inc.

Spalding, M.D., Fox, H.E., Allen, G.R., Davidson, N., Ferdaña, Z.A., Finlayson, M., Halpern, B.S., Jorge, M.A., Lombana, A., Lourie, S.A., Martin, K.D., Mcmanus, E., Molnar, J., Recchia, C.A. \& Robertson, J. (2007). Marine ecoregions of the world: A bioregionalization of coastal and shelf areas. BioScience $57,573$.

SteHLI, F.G. \& WeLLS, J.W. (1971). Diversity and age patterns in hermatypic corals. Systematic Zoology 20, 115.

Steininger, F.F. \& Rogl, F. (1984). Paleogeography and palinspastic reconstruction of the Neogene of the Mediterranean and Paratethys. Geological Society, London, Special Publications 17, 659-668.

TAVera, J., P, A., BALART, E.F. \& Bernardi, G. (2012). Molecular phylogeny of grunts (Teleostei, Haemulidae), with an emphasis on the ecology, evolution, and speciation history of New World species. BMC Evolutionary Biology 12, 57.

THACKER, C.E. (2015). Biogeography of goby lineages (Gobiiformes: Gobioidei): origin, invasions and extinction throughout the Cenozoic. Journal of Biogeography $\mathbf{4 2}$, $1615-1625$.

Thomson, R.C. \& SHAFFER, H.B. (2010). Rapid progress on the vertebrate tree of life. 
BMC Biology 8, 19.

Timm, J. \& KochziUs, M. (2008). Geological history and oceanography of the IndoMalay Archipelago shape the genetic population structure in the false clown anemonefish (Amphiprion ocellaris). Molecular Ecology 17, 3999-4014.

Tittensor, D.P., Mora, C., Jetz, W., Lotze, H.K., Ricard, D., Berghe, E. Vanden \& WORM, B. (2010). Global patterns and predictors of marine biodiversity across taxa. Nature 466, 1098-1101.

Toonen, R.J., Andrews, K.R., Baums, I.B., Bird, C.E., Concepcion, G.T., DalyEngel, T.S., Eble, J.A., Faucci, A., Gaither, M.R., Iacchei, M., Puritz, J.B., Schultz, J.K., Skillings, D.J., Timmers, M.A. \& Bowen, B.W. (2011). Defining boundaries for ecosystem-based management: a multispecies case study of marine connectivity across the Hawaiian Archipelago. Journal of Marine Biology 2011, 113.

Treml, E.A., Roberts, J., Halpin, P.N., Possingham, H.P. \& Riginos, C. (2015). The emergent geography of biophysical dispersal barriers across the Indo-West Pacific. Diversity and Distributions 21, 465-476.

TYLER, J.C. (1997) The Miocene fish Marosichthys, a putative Tetraodontiform, actually a perciform surgeon fish (Acanthuridae) related to the recent Naso. Beaufortia 47, $1-10$.

TYLER, J.C. (1999) A new genus and species of surgeon fish (Acanthuridae) with four dorsal-fin spines from the Eocene of Monte Bolca, Italy. Studi e Ricerche sui Giacimenti Terziari di Bolca 7, 257-268.

TyLER, J.C. (2000) Arambourgthurus, a new genus of hypurostegic surgeonfish (Acanthuridae) from the Oligocene of Iran, with a phylogeny of the Nasinae. Geodiversitas 22, 525-537.

TYler, J.C. \& Sorbini, L. (1998). On the relationships of Eonaso, an Antillean fossil surgeon fish (Acanthuridae). Studi e Ricerche sui Giacimenti Terziari di Bolca, Museo Civico di Storia Naturale di Verona 7, 35-42.

VermeiJ, G.J. (2001). Distribution, history, and taxonomy of the Thais clade (Gastropoda: Muricidae) in the Neogene of Tropical America. Paleontological Society 75, 697-705. 
1423 Veron, J.E.., Devantier, L.M., Turak, E., Green, A.L., Kininmonth, S.J., Stafford-

1424 Smith, M. \& Peterson, N. (2009). Delineating the Coral Triangle. Galaxea,

1425 Journal of Coral Reef Studies 11, 91-100.

1426 WeBB, C.O. \& REE, R. (2012). Historical biogeography inference in Southeast Asia. In

1427 Biotic Evolution and Environmental Change in Southeast Asia (eds D. GowER, K.

1428 Johnson, J. Richardson, B. Rosen, L. Ruber \& S. Williams), pp. 191-215.

1429 Cambridge Univ Press.

1430 Whiting, A. \& LAWLER, S. (2000). Biogeographic regionalization of Australia: assigning

1431 conservation priorities based on endemic freshwater crayfish phylogenetics. Animal

1432 Conservation 3, 155-163.

1433 Whittaker, R.J., Araujo, M.B., Paul, J., Ladle, R.J., Watson, J.E.M. \& Willis, K.J.

1434 (2005). Conservation Biogeography: assessment and prospect. Diversity and

1435 Distributions 11, 3-23.

1436 Willig, M.R., Kaufman, D.M. \& SteVens, R.D. (2003). Latitudinal gradients of

1437 biodiversity: pattern, process, scale, and synthesis. Annual Review of Ecology,

$1438 \quad$ Evolution, and Systematics 34, 273-309.

1439 WoodLAND, D.J. (1983). Zoogeography of the Siganidae (Pisces): an interpretation of

1440 distribution and richness patterns (Indo-Pacific). Bulletin of Marine Science 33,

1441 713-717.

1442

1443 
1444 Table 1. Geographic and phylogenetic sampling of endemic taxa by family. The number

1445 of species with geographic data across 13 common reef-associated families with the per

1446 cent of those taxa that are present in a phylogeny with age estimates in parentheses. ' $5 \%$

1447 End' and ' $10 \%$ End' are the number of species that are defined as endemic in the top 5\%

1448 or $10 \%$ of species ranked from smallest to largest geographic range size across the entire

1449 data set. 'Total GASPAR' is the number of species found in the 111 tropical ecoregion of

1450 the GASPAR data set (Parravicini et al., 2013).

\begin{tabular}{lllll}
\hline Family & $\begin{array}{l}\text { Species }(\% \\
\text { Phylogeny) }\end{array}$ & $\begin{array}{l}\mathbf{5 \%} \\
\text { End }\end{array}$ & $\begin{array}{l}\mathbf{1 0 \%} \\
\text { End }\end{array}$ & $\begin{array}{l}\text { Number of species } \\
\text { with age estimate }\end{array}$ \\
\hline Acanthuridae & $83(75.9 \%)$ & - & 1 & - \\
Apogonidae & $305(25.25 \%)$ & 9 & 17 & - \\
Blenniidae & $333(27.03 \%)$ & 22 & 42 & 4 \\
Carangidae & $99(57.58 \%)$ & 2 & 2 & 2 \\
Chaetodontidae & $127(75.59 \%)$ & 9 & 15 & 5 \\
Gobiidae & $722(13.85 \%)$ & 40 & 55 & 2 \\
Holocentridae & $71(59.15 \%)$ & 5 & 7 & 1 \\
Labridae & $448(43.08 \%)$ & 30 & 52 & 13 \\
Lutjanidae & $83(55.42 \%)$ & - & - & - \\
Mullidae & $49(16.33 \%)$ & 1 & 5 & - \\
Pomacanthidae & $86(48.84 \%)$ & 7 & 15 & 2 \\
Pomacentridae & $366(55.19 \%)$ & 27 & 44 & 7 \\
Sparidae & $99(70.71 \%)$ & 8 & 16 & 10 \\
\hline Total GASPAR & $6182(32.77 \%)$ & 322 & 604 & 103 \\
\hline
\end{tabular}




\section{Figure Legends}

1453

1454 Fig. 1. (A) Biodiverse regions in the marine tropics modified from Gaither \& Rocha

1455 (2013). IAA, Indo-Australian Archipelago following Bellwood \& Hughes (2001) and

1456 Renema et al. (2008); CT, Coral Triangle following Veron et al. (2009); IMP, Indo-

1457 Malay-Philippine biodiversity hotspot following Carpenter \& Springer (2005); InP, Indo-

1458 Polynesian biogeographic province modified from Briggs \& Bowen (2013); EH, endemic

1459 'biodiversity hotspots' based on endemism and assessments of threat following Roberts

1460 et al. (2002). (B) Tropical regions delineated bases on dissimilarity measure (Kulbicki et

1461 al., 2013). CIP, Central Indo-Pacific; CP, Central Pacific; EA, East Atlantic; TEP,

1462 Tropical East Pacific; WA, West Atlantic; WIO, West Indian Ocean. Global maps are

1463 drawn in Mollewide projection.

1464

1465 Fig. 2. Patterns of reef-associated fish biodiversity relating to (A) total species richness, 1466 (B) endemic species richness based on the top 10\% and (C) the top 5\% of species ranked 1467 from smallest to largest range size in the sampled data set (Parravicini et al., 2013). (D)

1468 Fish endemic species richness based on species that are restricted to a single ecoregion.

1469 Ecoregion scheme follows Spalding et al. (2007). The top margin of each map displays a

1470 density plot for each measure across longitude. Maps drawn in Mollewide projection.

1472 Fig. 3. (A) Proportion of endemic reef fish species (top 10\% of smallest ranges) found

1473 across tropical ecoregions. Size of circles indicates per cent of assemblage made up by

1474 endemic species. Colour of circle denotes if those species are considered neo-endemics

1475 (orange, $\leq 2.6 \mathrm{Ma}$ ), paleo-endemics (purple, $>2.6 \mathrm{Ma}$ ) or a mixture of both (green).

1476 Number next to each coloured point indicates the number of neo- and paleo-endemics

1477 with age estimates at that ecoregion. Ecoregions where no age estimates were available

1478 are in white, and ecoregions with no endemic species based on the $10 \%$ definition are not

1479 shown. (B) Temporal distribution of endemic lineages and whether they are considered

1480 neo- or paleo-endemic. Bin widths represents 0.3 million years and $y$-axis is scaled to per

1481 cent of all endemic age estimates sampled (103 lineages total). 
1483 Fig. 4. Tropical provinciality of extant reef fish assemblages based on phylogenetic

1484 dissimilarity clustering methods. (A) Map of ecoregions; colour indicates their

1485 association with a particular cluster. (B) Dendrogram showing the clustering of

1486 ecoregions based on phylogenetic dissimilarity. Coloured branches are linked to cluster

1487 colours in A. E* indicates the clustering of distant Pacific Islands linked by endemic taxa

1488 formed through peripheral isolation processes (see text). Cluster analysis produces a

1489 quantitative, hierarchical classification of the dissimilarity among species assemblages,

1490 but is sensitive to the dissimilarity measure and the classification algorithm chosen.

1491 Amongst the myriad of dissimilarity indices available (most reviewed in Koleff et

1492 al., 2003) we chose a metric based on species turnover as these are insensitive to

1493 variation in species richness, which may blur biogeographic patterns. Since our analysis

1494 was conducted across lineages and evolutionary time, instead of a turnover measure

1495 based on species we chose a recently developed measure of turnover based on lineages

1496 across the phylogenetic tree (Leprieur et al., 2012) as this has the advantage of giving

1497 different weight to the dissimilarity among assemblages while accounting for

1498 phylogenetic distance among lineages. Clustering using the Unweighted Pair Group

1499 Method with Arithmetic Mean (UPGMA) algorithm achieved the best performance and

1500 was retained for further analysis in time slices (see Fig. 6).

1502 Fig. 5. Composite time-calibrated phylogenetic tree for 11 reef-associated fish families 1503 and their presence/absence in present-day phylogenetic dissimilarity clusters (see Fig. 4).

1504 Colours at tips correspond to cluster colours in Fig. 4. Geological epochs are denoted on 1505 the time axis (Pe: Pleistocene; Pi: Pliocene).

1507 Fig. 6. Tropical provinciality through time at 3 million year time steps (3-27 Ma). Each

1508 panel displays the global continental reconstruction for that time period, the reconstructed 1509 ecoregion clusters based on phylogenetic dissimilarity of lineages with ancestral

1510 biogeographic estimation, and the associated cluster dendrogram with corresponding 1511 cluster colours. Light- and dark-grey backgrounds indicate whether the time step is found 1512 in the Pliocene, Miocene or Oligocene epochs. For each dendrogram, the optimal number 1513 of biogeographic clusters was determined by applying the Kelley-Gardner-Sutcliffe 
1514 penalty function (KGS). This function maximizes differences between the groups and 1515 cohesiveness within the groups. Its minimum value corresponds to the optimal number of 1516 clusters (Kelley et al., 1997; Hattab et al., 2015).

1517

1518

1519

1520

1521

1522

1523

1524

1525

1526

1527

1528

1529

1530

1531

1532

1533

1534

1535

1536

1537

1538

1539

1540

1541

1542

1543

1544

1545

1546

1547

1548

1549

1550

1551

1552

1553

1554

1555

1556

1557

1558

1559

1560

1561

1562

1563

1564

1565

1566 
1567 Figure 1
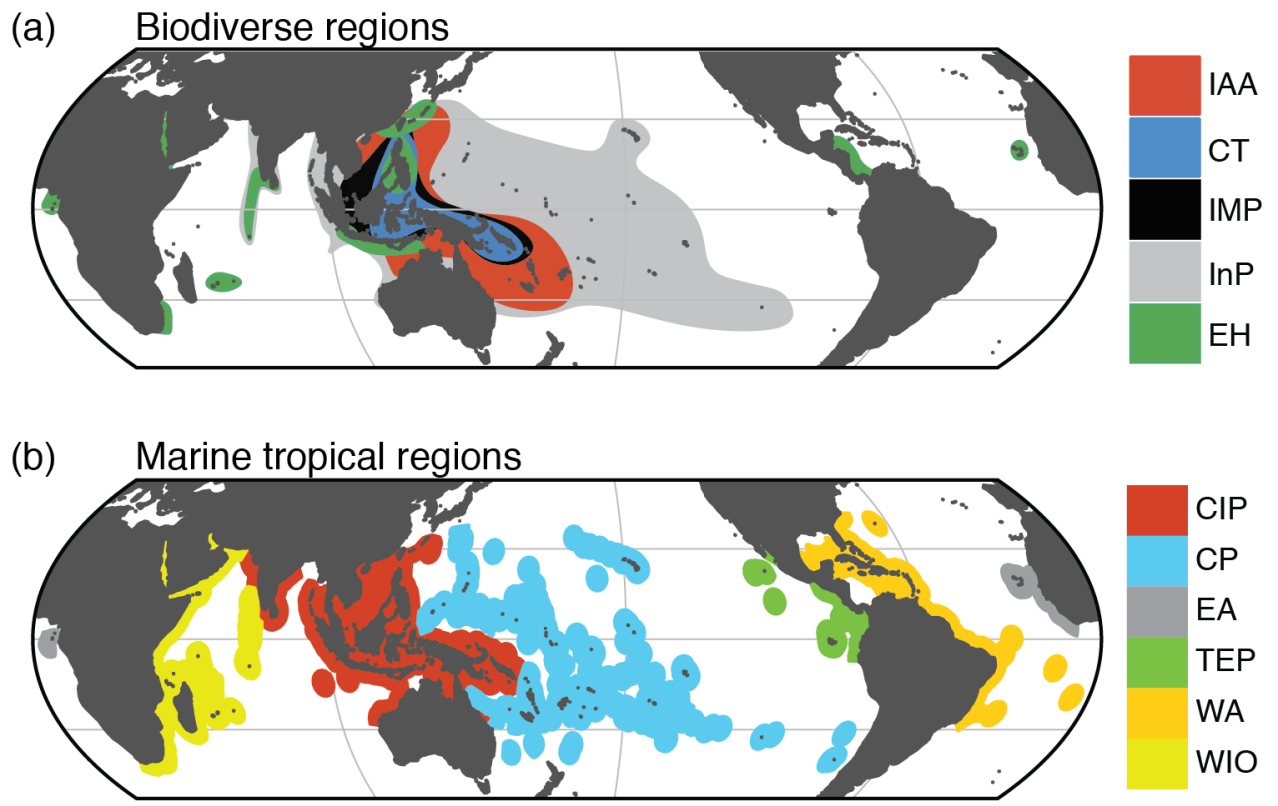

1568

1569

1570

1571

1572

1573

1574

1575

1576

1577

1578

1579

1580

1581

1582

1583

1584

1585

1586

1587

1588

1589

1590

1591

1592

1593

1594

1595

1596

1597

1598

1599

1600 
1601

1602

(a) Species richness

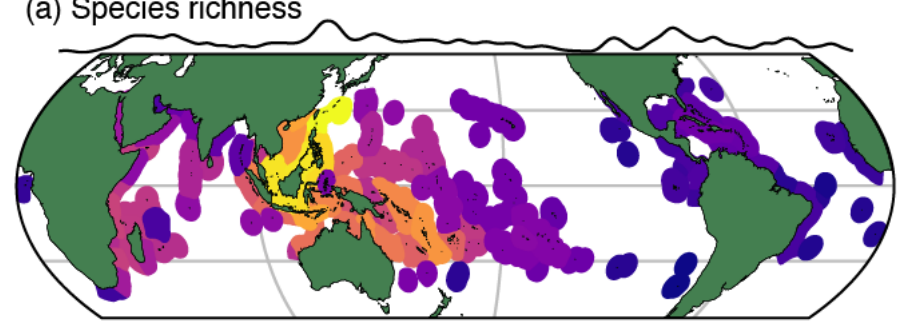

(b) Endemic species richness (Top 10\% smallest range)

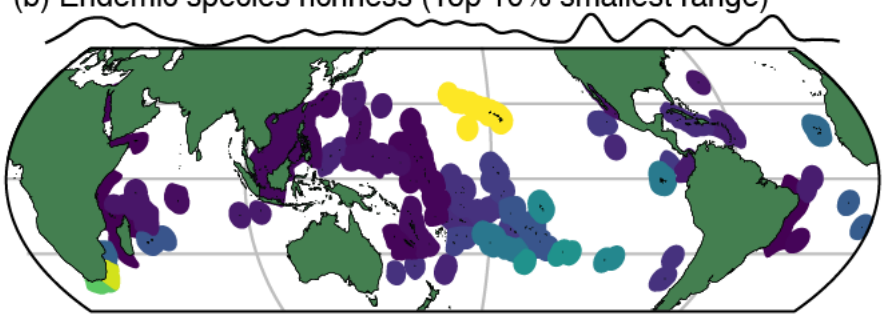

(c) Endemic species richness (Top 5\% smallest range)

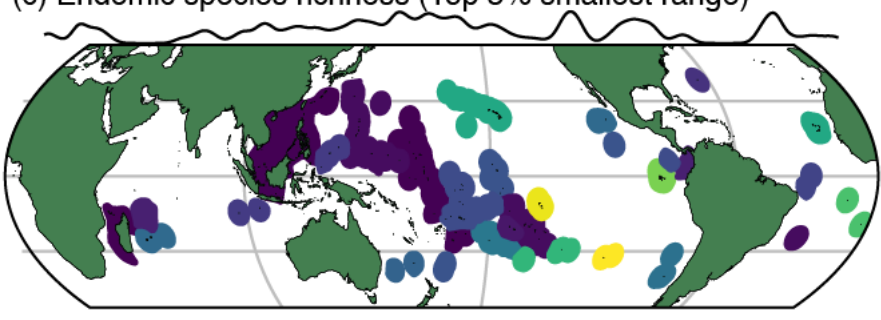

(d) Endemic species richness (by ecoregion)

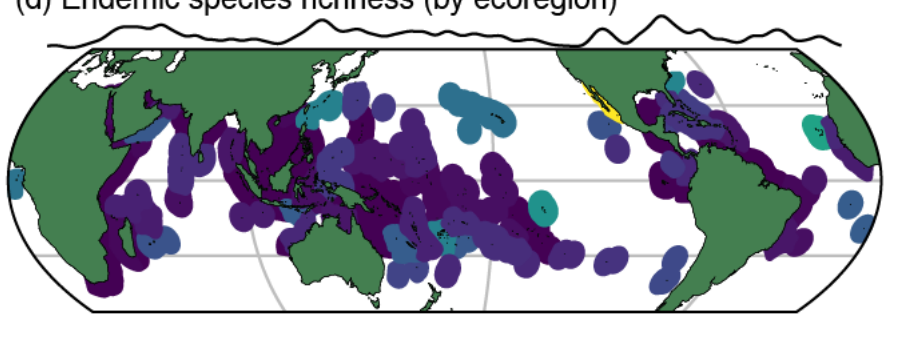

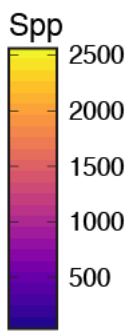
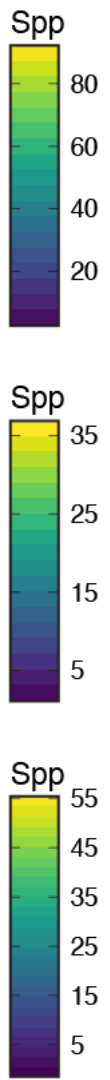

1603

1605

1606

1607

1608

1609

1610

1611

1612

1613

1614

1615

1616

1617

1618

1619

1620 
1621 Figure 3

1622

(a)

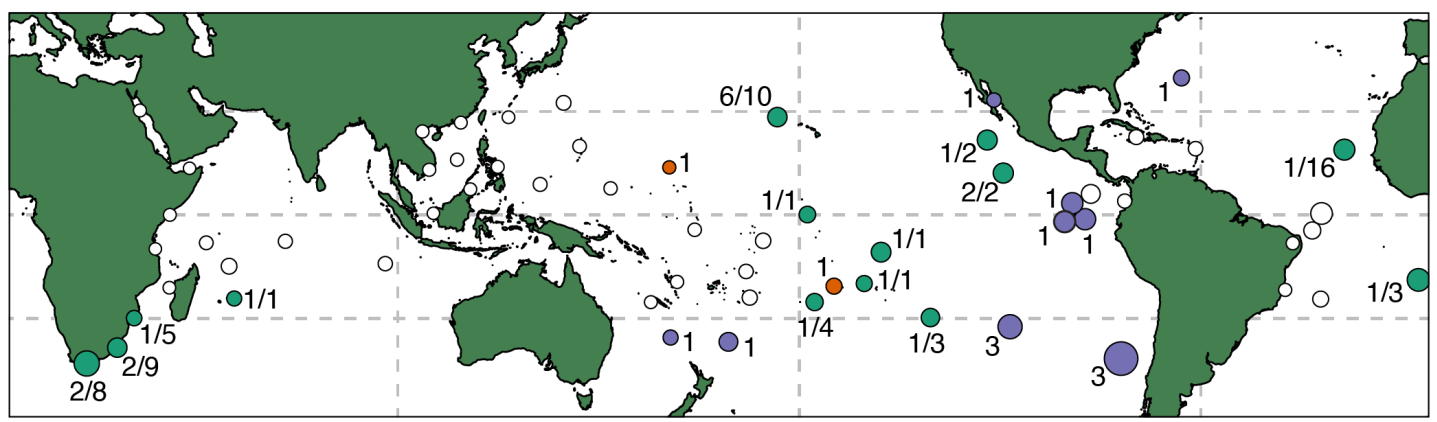

Neo-Endemic $\bigcirc$ Paleo-Endemic $\bigcirc$ mixed $\bigcirc$ No Age Available $\bigcirc \geq 30 \bigcirc 30-10 \% \quad \bigcirc 10-1 \% \quad \bigcirc \leq 1 \%$

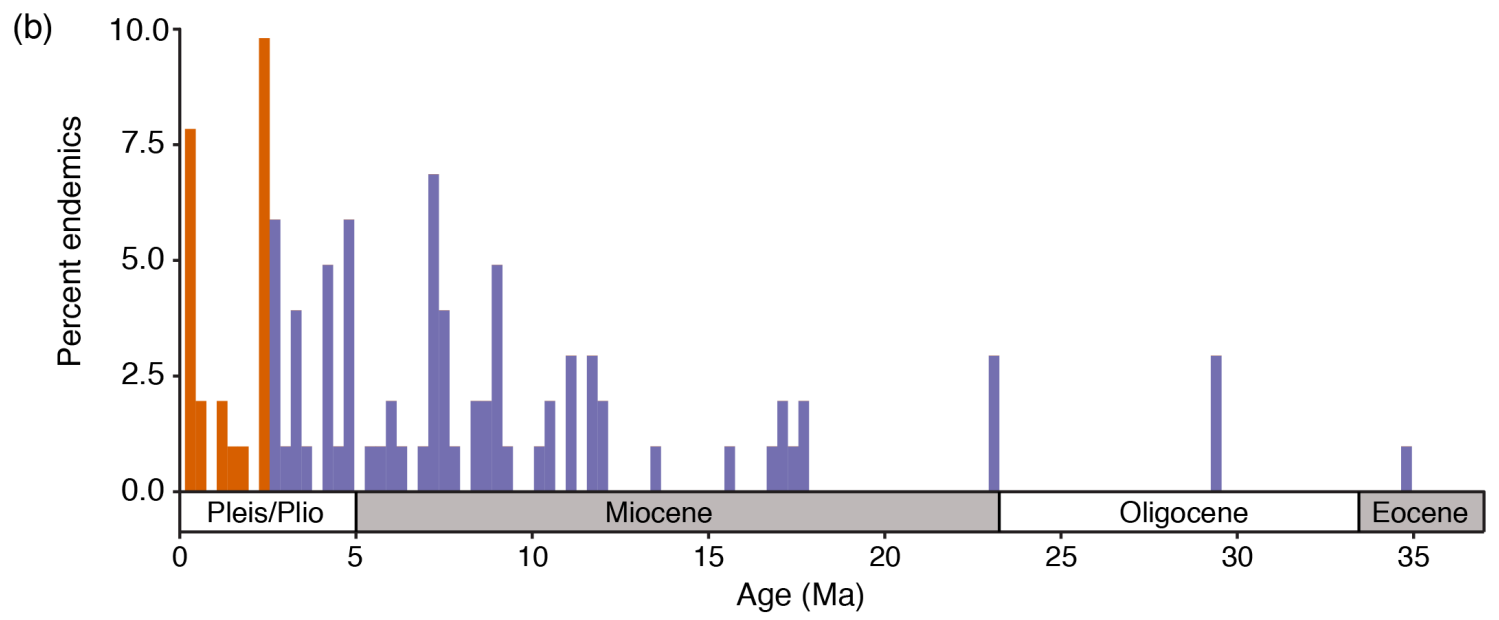

1623

1625

1626

1627

1628

1629

1630

1631

1632

1633

1634

1635

1636

1637

1638

1639

1640

1641

1642

1643

1644

1645

1646 
(a) Map of present day assemblage clusters - 7 clusters

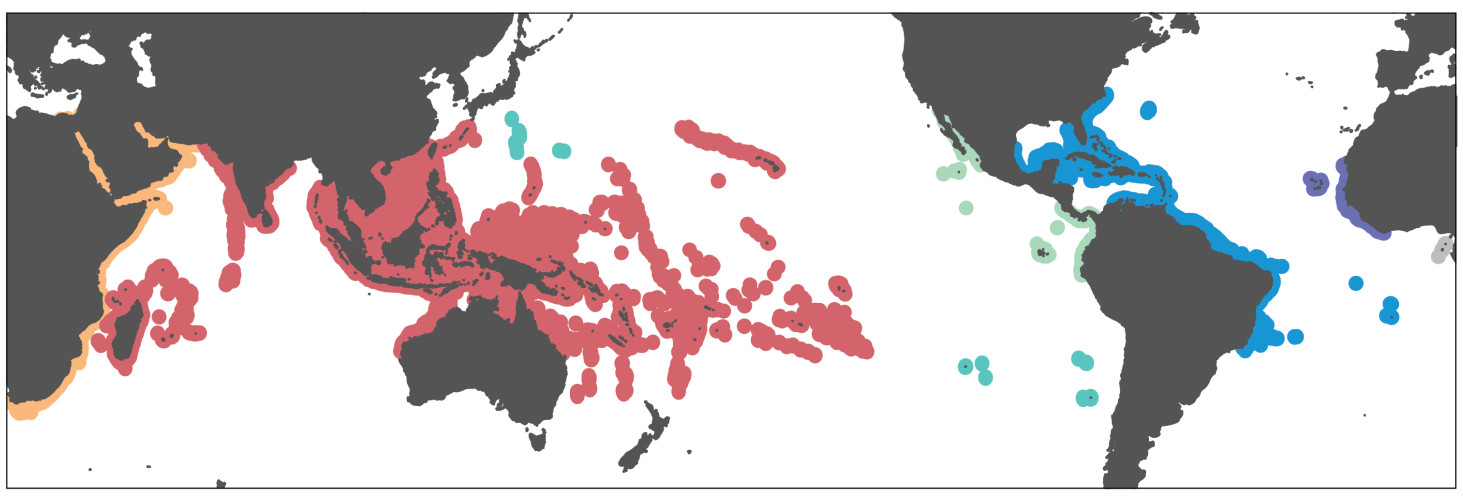

(b) Phylogentically informed cluster diagram of assemblage dissimilarity

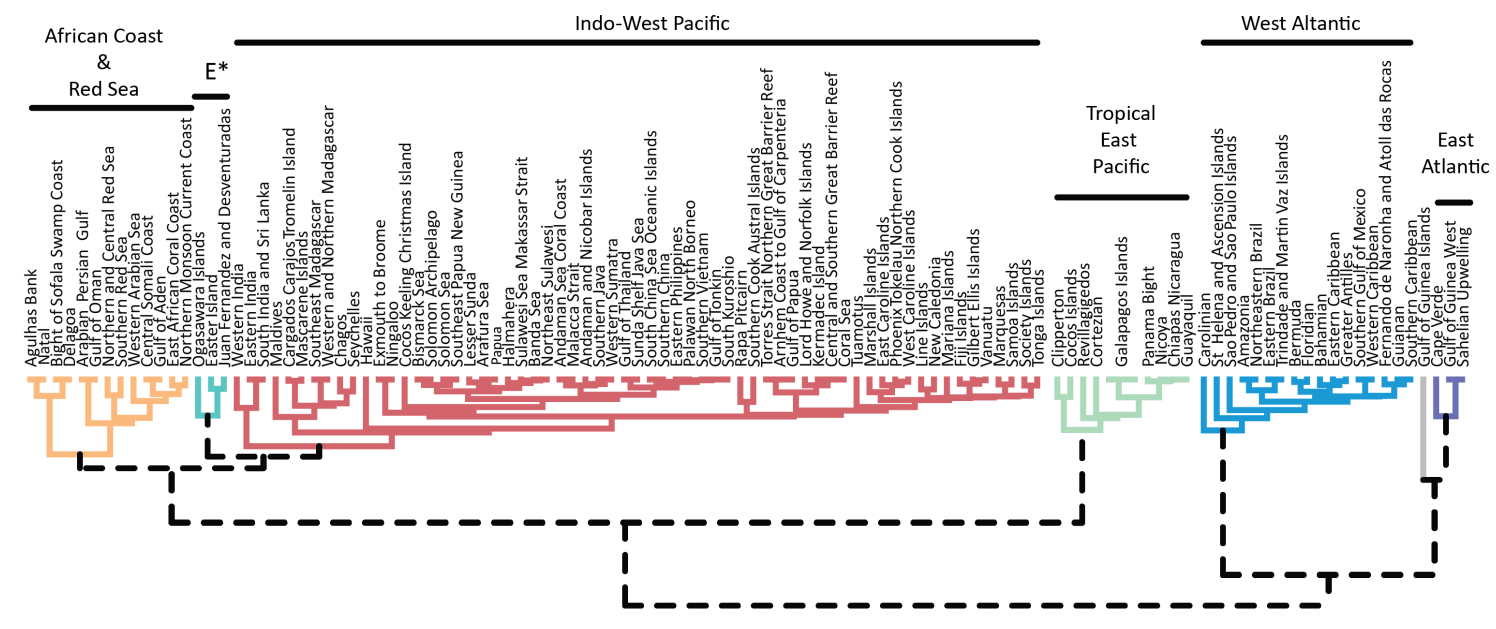


1673 Figure 5 

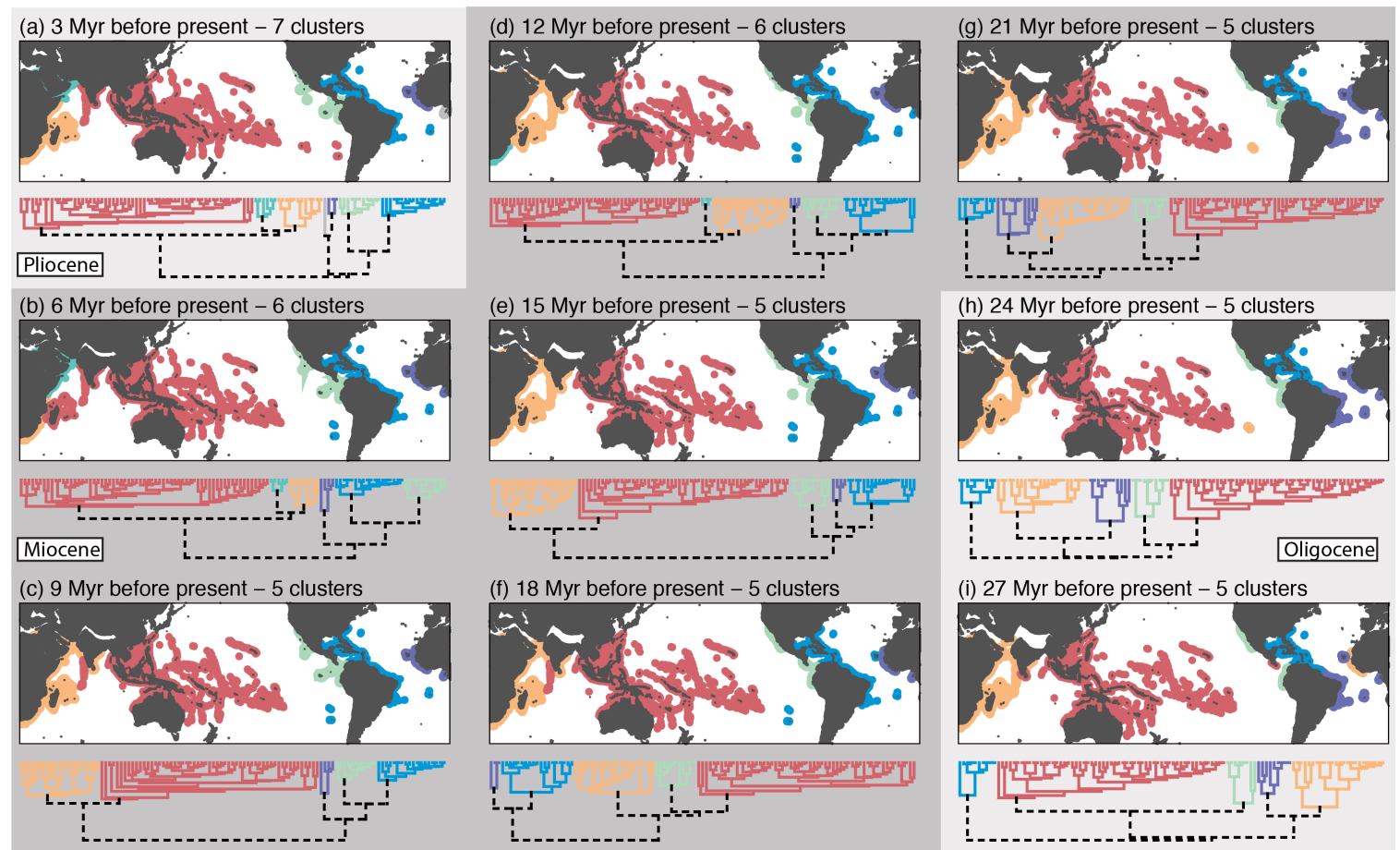

(f) $18 \mathrm{Myr}$ before present -5 clusters
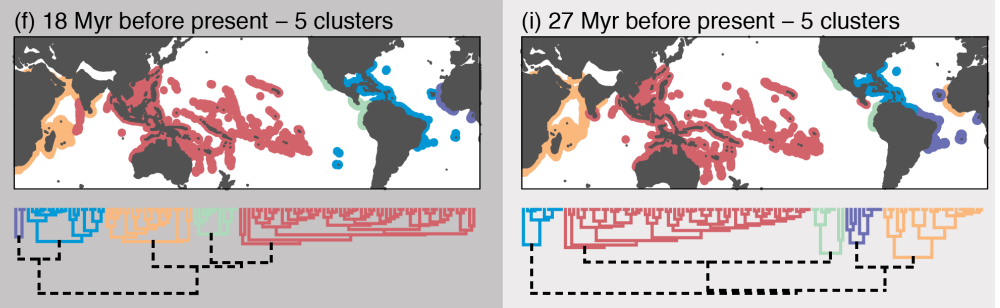